\title{
Differential stress reaction of human colon cells to oleic-acid-stabilized and unstabilized ultrasmall iron oxide nanoparticles
}

This article was published in the following Dove Press journal:

International Journal of Nanomedicine

23 July 2014

Number of times this article has been viewed

\author{
Catherine A Schütz',* \\ Davide Staedler ${ }^{2, *}$ \\ Kieran Crosbie-Staunton ${ }^{3}$ \\ Dania Movia ${ }^{4}$ \\ Catherine Chapuis \\ Bernasconi \\ Blanka Halamoda Kenzaoui' \\ Adriele Prina-Mello ${ }^{3,4}$ \\ Lucienne Juillerat- \\ Jeanneret ${ }^{\prime}$ \\ 'Centre Hospitalier Universitaire \\ Vaudois (CHUV), UNIL, ' Institute \\ of Chemical Sciences and Engineering, \\ EPFL, CH-I0I5, Lausanne, Switzerland \\ ${ }^{3}$ School of Medicine, ${ }^{4}$ CRANN, Trinity \\ College Dublin, Dublin, Ireland
}

*These authors contributed equally to this work
Correspondence: Lucienne JuilleratJeanneret

University Institute of Pathology, rue du Bugnon 25, CH-IOII, Lausanne, Switzerland

$\mathrm{Tel}+4|2| 3|47| 73$

Fax $+4 \mid 213147115$

Email lucienne.juillerat@chuv.ch

Adriele Prina-Mello Institute of Molecular Medicine, Trinity

Centre for Health Sciences, St James

Street, Dublin 8, Ireland

Tel +353 I 8963087

Email prinamea@tcd.ie
Abstract: Therapeutic engineered nanoparticles (NPs), including ultrasmall superparamagnetic iron oxide (USPIO) NPs, may accumulate in the lower digestive tract following ingestion or injection. In order to evaluate the reaction of human colon cells to USPIO NPs, the effects of non-stabilized USPIO NPs (NS-USPIO NPs), oleic-acid-stabilized USPIO NPs (OA-USPIO NPs), and free oleic acid (OA) were compared in human HT29 and $\mathrm{CaCo}_{2}$ colon epithelial cancer cells. First the biophysical characteristics of NS-USPIO NPs and OA-USPIO NPs in water, in cell culture medium supplemented with fetal calf serum, and in cell culture medium preconditioned by HT29 and $\mathrm{CaCo}_{2}$ cells were determined. Then, stress responses of the cells were evaluated following exposure to NS-USPIO NPs, OA-USPIO NPs, and free OA. No modification of the cytoskeletal actin network was observed. Cell response to stress, including markers of apoptosis and DNA repair, oxidative stress and degradative/autophagic stress, induction of heat shock protein, or lipid metabolism was determined in cells exposed to the two NPs. Induction of an autophagic response was observed in the two cell lines for both NPs but not free OA, while the other stress responses were cell- and NP-specific. The formation of lipid vacuoles/droplets was demonstrated in HT29 and $\mathrm{CaCo}_{2}$ cells exposed to OA-USPIO NPs but not to NS-USPIO NPs, and to a much lower level in cells exposed to equimolar concentrations of free OA. Therefore, the induction of lipid vacuoles in colon cells exposed to OA utilized as a stabilizer for USPIO NPs is higly amplified compared to free OA, and is not observed in the absence of this lipid in NS-USPIO NPs.

Keywords: oleic acid, ultrasmall iron oxide nanoparticles, human colon cells, lipid vacuoles, stress reaction, heat shock proteins

\section{Introduction}

Nanotechnology and the extended use of nanomaterials in nanomedicine is a rapidly developing field. ${ }^{1-3}$ Nanomaterials are materials with one, two, or three dimensions in the nanoscale, while nanoparticles (NPs) are usually defined as systems for which all three dimensions are roughly 1 to $100 \mathrm{~nm}$. In the field of nanomedicine, the acceptance of this definition extends to particles or nanotherapeutics with dimensions up to $1,000 \mathrm{~nm}$. Since the initial development of therapeutic NPs, the field of nanotechnology has gained a lot of interest due to their huge potential for applications in industry and medicine. The primary goals of nanoparticulate systems in nanomedicine are to target specific tissues or cells, to deliver drugs in a controlled manner, thus lowering the necessary dose of chemotherapeutics for therapeutic efficacy together with decreasing the toxicity of the corresponding treatment to alleviate the side effects of chemotherapeutics. However, the biocompatibility of therapeutic NPs must be ensured and their intrinsic toxicity must be controlled so that it does not overtake the benefits of decreasing the toxicity of 
the drugs or treatments. Therefore, a deep understanding of their interactions with living tissues and knowledge of their possible effects in the human body are necessary for the safe use of nanoparticulate formulations. However, the knowledge about the possible interactions of engineered therapeutic NPs with living cells and tissues and their metabolic fate presently are not complete or well-defined.

After ingestion or intravenous injection, therapeutic NPs may reach the lower digestive tract. The effects of the interaction of NPs, in particular of metal-based solid-core NPs, with the colon epithelia, the potential toxicity profile of NPs, and the evaluation of the effects of NPs' exposure on the functional response of colon cells are currently limited. It is generally accepted that not only the size, but also the chemical composition, surface chemistry, charge, and shape are relevant for considering the behavior of NPs in the biological environment.

Ultrasmall superparamagnetic iron oxide (USPIO) NPs were initially developed as therapeutic and diagnostic agents in nanomedicine for magnetic resonance imaging, for perfusion imaging, and for angiography and tumor vascular imaging. Their uses have been recently extended to new applications. ${ }^{4-7}$ We have previously shown that USPIO NPs are taken up by human cells, even when functionalized with a fluorophore ${ }^{8,9}$ or with therapeutic anticancer agents, ${ }^{10,11}$ but that the biochemical characteristics of the surface functionalization of the NPs were important for their cellular trafficking and the reaction of the cells to their uptake. In particular, we had observed that the intracellular localization of cationic USPIO NPs functionalized with hydrophilic or hydrophobic drugs was dependent on the lipophilicity of the drugs. ${ }^{10,11}$ We have also previously shown that monolayers and spheroids of human colon cells can internalize cationic USPIO NPs, but cannot release or transport them across models of the human colon epithelial barrier. ${ }^{12}$ In the present study, in order to further evaluate the effects of the biophysical characteritics of USPIO NPs in human colon cells, we compared the reaction of human HT29 and $\mathrm{CaCo}_{2}$ colon epithelial cells to deeply characterized non-stabilized (bare) and oleic-acid-stabilized USPIO NPs, demonstrating that the main colon cell stress response was the induction of high amounts of large lipid vacuoles dependent on the oleic acid stabilizer of the USPIO NPs, but not on free oleic acid or the iron oxide core.

\section{Materials and methods NPs}

Non-stabilized USPIO NPs $\left(\mathrm{Fe}_{3} \mathrm{O}_{4}\right.$; NS-USPIO NPs) were purchased from PlasmaChem (PlasmaChem $\mathrm{GmbH}$,
Adlershof, Germany) as a $\sim 3 \%$ nanosuspension in water with a nominal NP size of $8 \pm 3 \mathrm{~nm}$ (as determined by dynamic light scattering [DLS], value provided by the provider) and $18 \mathrm{mg}$ iron/mL by quantitative Prussian Blue reaction. Oleicacid-stabilized USPIO NPs $\left(\mathrm{Fe}_{3} \mathrm{O}_{4}, 3 \%\right.$ oleic acid coating; OA-USPIO NPs) were obtained from PlasmaChem as a $\sim 7 \%$ nanosuspension in water with a nominal particle iron oxide core size of $8 \pm 3 \mathrm{~nm}$, a hydrodynamic size of 14-15 nm (both values determined by DLS by the provider), and $206 \mathrm{mg}$ iron/mL by quantitative Prussian Blue reaction.

\section{Physicochemical characterization of the USPIO NPs}

The nominal size of both USPIO-NPs was measured by transmission electron microscopy (TEM) using asreceived material and Holey carbon 300 mesh copper grids (Polysciences, Warrington, PA, USA) to confirm the supplier data provided. NP properties and stability characteristics were assessed at Trinity College Dublin; NPs were placed in ultrapure deionized water for 24 hours, then the NPs were incubated in 10\% heat-inactivated fetal calf serum (FCS) in phosphate-buffered saline (PBS), in Dulbecco's Modified Eagle's Medium (DMEM) culture medium, in DMEM containing 10\% FCS, or in cell culture medium preconditioned for 72 hours by the $\mathrm{CaCo}_{2}$ and HT29 cells $\left(\mathrm{CaCo}_{2}-\mathrm{CM}\right.$ and HT29-CM). Stock solutions of NS-USPIO NPs and OA-USPIO NPs were vortexed for 5 seconds to disperse the particles evenly and then diluted in the relevant solutions. NS-USPIO NP and OA-USPIO NP characterization was carried out for the identification of nominal and hydrodynamic radii, zeta potentials, colloidal and aggregation stabilities by DLS (Malvern Zetasizer; Malvern Instruments, Malvern, UK), and NP tracking analysis (NTA; Nanosight NS500; Malvern Instruments) of the two NPs dispersed in the different biological matrices after vortexing for 5 seconds. Three USPIO NP concentrations were used (eg, 25, 50, and $100 \mu \mathrm{g} / \mathrm{mL}$ ). All measurements were carried out three times at physiologically relevant $\mathrm{pH}(\mathrm{pH}=7)$ and averages and standard deviations (SDs) are reported. For both techniques, hydrodynamic radius and polydispersity index (PDI) were measured at room temperature using single depth position, recording six videos of 90 seconds each. Quality assurance over the measurements carried out was guaranteed by the adoption of Quality Nano (QNano, FP7 project) standard operating procedures, which have been developed as part of large inter-laboratory comparative study focused on NP physicochemical characterization. ${ }^{13}$ 


\section{Cell models and culture conditions}

Human HT29 and $\mathrm{CaCo}_{2}$ colon cancer cells were obtained from the American Tissue Culture Collection (Manassas, VA, USA). Cells were grown in DMEM containing $4.5 \mathrm{~g} / \mathrm{L}$ glucose, $10 \%$ heat-inactivated FCS, and penicillin/streptomycin (all cell culture reagents from Invitrogen; Thermo Fisher Scientific, Waltham, MA, USA). To obtain cell-conditioned medium (cell-CM), HT29 and $\mathrm{CaCo}_{2}$ cells were grown to $75 \%$ confluence, the medium was changed to fresh complete medium and cell-CM was harvested after 3 days, centrifuged, and stored in aliquots at $-20^{\circ} \mathrm{C}$.

\section{Cell uptake of USPIO NPs}

Cells were grown in 48-well plates (Costar; Corning Incorporated, Corning, NY, USA) until $75 \%$ confluent, and exposed to NPs diluted in DMEM with $10 \%$ FCS without phenol red (Invitrogen) for 24 hours at the concentrations and for the time indicated. Cell-associated iron was quantified using the Prussian Blue reaction essentially as previously described. ${ }^{12}$ Briefly, the cell layers were dissolved at room temperature for 1 hour in $6 \mathrm{M} \mathrm{HCl}(125 \mu \mathrm{L} /$ well $)$, then $125 \mu \mathrm{L}$ of a $5 \%$ weight/volume (w/v) solution of $\mathrm{K}_{4}\left[\mathrm{Fe}(\mathrm{CN})_{6}\right] \cdot 3 \mathrm{H}_{2} \mathrm{O}$ (EMD Millipore, Billerica, MA, USA) in water was added for 10 minutes and the absorbance was read at $690 \mathrm{~nm}$ in a multi-well plate reader (iEMS Reader; Labsystems, BioConcept Ltd., Allschwil, Switzerland). A standard curve of iron chloride in $6 \mathrm{M} \mathrm{HCl}$ treated under the same conditions was used to quantify the amount of cell-bound iron. All experiments were performed in triplicate wells, and repeated twice. Means \pm SDs were calculated.

\section{Determination of cytotoxicity}

Cells were exposed to the NPs or to oleic acid (EMD Millipore) at the concentrations and for the time indicated. Following exposure, cell viability was evaluated using the 3-(4,5-dimethyl-2-thiazoyl)-2,5-diphenyltetrazolium bromide (MTT) assay $(200 \mu \mathrm{g} / \mathrm{mL}$ final concentration; Sigma-Aldrich Co., St Louis, MO, USA), essentially as previously described. ${ }^{12}$ Absorbance at $540 \mathrm{~nm}$ was measured in a multi-well plate reader (iEMS Reader; BioConcept Ltd.), and the absorbance values of treated cells were compared with the absorbance values of untreated cells. The interference of the NPs with the assay was controlled as described in more detail elsewhere and no interference was observed in the conditions of our assay. ${ }^{14}$ Experiments were conducted in triplicate wells and repeated twice. Means \pm SDs were calculated. Statistical significance was ascertained using a Student's $t$-test.

\section{Histochemical determination of iron and lipids}

For histological iron determination, after exposure to USPIO NPs or to oleic acid, the cell layers were washed with saline and incubated for 20 minutes at room temperature with a 1:1 solution of $10 \% \mathrm{HCl}$ and $10 \% \mathrm{~K}_{4}\left[\mathrm{Fe}(\mathrm{CN})_{6}\right] 3 \mathrm{H}_{2} \mathrm{O}$ in $\mathrm{H}_{2} \mathrm{O}$, washed with distilled water, counterstained with Nuclear Fast Red (EMD Millipore), dehydrated in graded ethanol to xylol, and mounted. Slides were photographed under a Nikon digital camera (DXM 1200; Nikon Corporation, Tokyo, Japan). For histological lipid determination, after exposure to the NPs or to oleic acid, the cell layers were washed with PBS, fixed in $4 \%$ buffered formaldehyde at $4^{\circ} \mathrm{C}$ for 30 minutes and the histological Prussian Blue reaction was performed first, washed once with distilled water, then stained with Oil-O-Red (saturated solution in isopropanol, diluted 3:2 in distilled water; EMD Millipore), counterstained with hematoxylin (Sigma-Aldrich Co.) and mounted in Pertex (Leica Biosystems, Wetzlar, Germany). Slides were photographed under a Nikon digital camera (DXM 1200; Nikon Corporation).

\section{TEM for cell imaging}

Cells were grown in $9 \mathrm{~cm}$ diameter Petri dishes (Becton, Dickinson and Company, Franklin Lakes, NJ, USA) and exposed to the NPs or oleic acid for the appropriate times. Cells were washed twice with PBS, fixed in $2 \%$ glutaraldehyde buffered in $0.1 \mathrm{M}$ cacodylate for 1 hour at $4^{\circ} \mathrm{C}$, then washed in $0.2 \mathrm{M}$ cacodylate at $4^{\circ} \mathrm{C}$ (three times for 10 minutes), gently scraped in $0.2 \mathrm{M}$ cacodylate and harvested by centrifugation ( 5 minutes at 1,000 rpm). The pellets were coated with agarose (type III low gelling temperature; Sigma-Aldrich Co.) and cut in small pieces. The samples were postfixed in $1 \%-2 \%$ buffered osmium tetroxide for 1 hour at room temperature, washed in $0.2 \mathrm{M}$ cacodylate (twice for $5 \mathrm{~min}$ utes), dehydrated in graded ethanol (twice for 10 minutes in $70 \%$ ethanol, twice for 10 minutes in $90 \%$ ethanol, and three times for 20 minutes in $100 \%$ ethanol), dehydrated again in propylene oxide (twice for 30 minutes), embedded in equal volumes of propylene oxide and Epon (50\% Epon 812 substitute, 26\% dodecenylsuccinic anhydride, $23 \%$ methyl nadic anhydride, 1\% 2,4,6-tris[dimethylaminomethyl]phenol); all dilutions w/v, all chemicals from Fluka; Sigma-Aldrich Co.) for 1 hour, and then embedded for 16 hours in Epon. Specimens were embedded in Epon blocks that were cured for 48 hours at $60^{\circ} \mathrm{C}$, and then trimmed and cut into $100 \mathrm{~nm}$ sections and mounted on slides for post-visualization by methylene blue/azure blue staining. Thin sections $(50 \mathrm{~nm})$ 
were cut from the cured blocks using an ultramicrotome (Ultracut E; Reichert-Jung Optische Werke AG, Wien, Austria) and mounted on $3 \mathrm{~mm}$ 200-mesh copper grids. Grids were heavy-metal stained using a standard two-step uranyl acetate/lead citrate technique (Leica EM Stain; Leica Microsystems, Wetzlar, Germany) and then examined and photographed at $80 \mathrm{kV}$ with a Philips CM12 transmission electron microscope (Philips International B.V., Amsterdam, the Netherlands) combined with a MegaView III, Soft Imaging System (Gloor Instruments AG, Kloten, Switzerland). The quantification of the number per cell and diameter of the lipid vacuoles were determined on TEM images obtained at $2 \mu \mathrm{m}$ resolution of single cells without prior selection ( $>20$ per treatment) using the ImageJ software (imagej.net; National Institutes of Health, Bethesda, Maryland, USA) and were then represented in boxplot figures. Normality of the data was tested using the Shapiro-Wilk test, and statistical significance was ascertained using the Wilcoxon-MannWhitney test.

\section{Acetate incorporation}

Radioactive acetate incorporation was performed according to the protocol published by Beckers et al. ${ }^{15}$ The cells were seeded and grown in 6-well plates (Costar; Corning Incorporated) for 48 hours, then exposed to the NPs or to oleic acid for 24 hours. Six hours prior to the end of the treatment, etomoxir $(10 \mu \mathrm{g} / \mathrm{mL}$, an inhibitor of fatty acid oxidation; Sigma-Aldrich Co.) and $\left[{ }^{14} \mathrm{C}\right]$ sodium acetate (10 nCi/mL final concentration; American Radiolabeled Chemicals, Inc., St Louis, MO, USA) were added to the cells for 24 hours. The cell layers were precipitated with $10 \%$ trichloroacetic acid, then dissolved in $0.1 \%$ sodium dodecyl sulfate in $0.1 \mathrm{~N} \mathrm{NaOH}$ and $4.5 \mathrm{~mL}$ scintillation cocktail (Optiphase HI-Safe; PerkinElmer Inc., Waltham, MA, USA). Radioactivity was counted in a $\beta$-counter (WinSpectra, Wallac, Finland). The radioactivity counts of treated cells were compared to the radioactivity counts of untreated cells. Cellular protein concentration was determined using the bicinchoninic acid protein assay, according to the provider's instructions (Pierce BCA Protein Assay Kit; Thermo Fisher Scientific) using bovine serum albumin (BSA) as the standard. Measurements were performed in triplicate and repeated three times. Means \pm SDs were calculated. Statistical significance was ascertained using a Student's $t$-test.

\section{Western blotting experiments}

Cells were grown in $9 \mathrm{~cm}$ diameter Petri dishes (Becton, Dickinson and Company) and exposed to the NPs or oleic acid for the appropriate times. Following treatments, the cell layers were washed once with cold PBS and lysed in $250 \mu \mathrm{L}$ of lysis solution (17.6 mM Tris- $\mathrm{HCl}$, $120.56 \mathrm{mM} \mathrm{NaCl}, 8.8 \%$ volume/volume glycerol, $0.88 \%$ volume/volume NP40, 0.88\% w/v CHAPS, $2 \mathrm{mM}$ vanadate, $50 \mathrm{mM} \mathrm{NaF}, \mathrm{pH} 7.85$ ) and $10 \mu \mathrm{L}$ of proteinase inhibitor cocktail (Sigma-Aldrich Co.), and extracted by four cycles of freeze/thawing. Supernatants were submitted to sodium dodecylsulfate-polyacrylamide gel electrophoresis (SDS-PAGE) and transferred onto a nitrocellulose membrane (Whatman; GE Healthcare Europe GmbH, Freiburg, Germany). The membranes were blocked with $5 \%$ fat-free milk in PBS, 5\% BSA in PBS, washed in 0.05\% Tween-20 (Sigma-Aldrich Co.) in PBS, and incubated overnight at $4{ }^{\circ} \mathrm{C}$ with the primary antibodies diluted in $1 \%$ fat-free milk or $1 \%$ BSA in $0.05 \%$ Tween-20 in PBS. Membranes were then exposed for 1 hour at room temperature to peroxidase-conjugated secondary antibodies and visualized using chemoluminescence (ECL; GE Healthcare UK Ltd, Little Chalfont, UK). The primary and secondary antibodies, buffers, and dilutions used are summarized in Supplementary material, Table S1. To control for loading, the membranes were stripped by successive incubation in $0.1 \mathrm{M}$ glycine pH 2.3, $1 \mathrm{M} \mathrm{NaCl}$ in PBS, and $0.05 \%$ Tween 20 in PBS, blocked for 1 hour with 5\% fat-free milk in PBS, and exposed to a polyclonal anti-human $\beta$-actin rabbit antibody (diluted 1:5,000; Sigma-Aldrich Co.) for 1 hour at room temperature and treated as washed and visualized. For densitometric analysis, the protein band areas were evaluated using ImageJ software (imagej. net; National Institutes of Health), then the ratio of the band area of each protein to the area of the actin band was determined.

\section{Glutathione-S-transferase (GST) activity}

The activity of GST in cell extracts was determined using 1-chloro-2,4-dinitrobenzene (CDNB) and glutathione (GSH) as previously described. ${ }^{16}$ Briefly, cells were grown for 24 hours in $9 \mathrm{~cm}$ diameter Petri dishes (Becton, Dickinson and Company) and exposed to the NPs or oleic acid for 72 hours. Then, the cell layers were scraped in cold pH 6.5 PBS, extracted by 4 cycles of freezing/thawing, and centrifuged at $10,000 \mathrm{rpm}$ at $4^{\circ} \mathrm{C}$ for 10 minutes and the supernatants were collected. The GST activity in the supernatants was determined by measuring the increase in absorbance at $340 \mathrm{~nm}$ in a multi-well plate reader (iEMS Reader; BioConcept Ltd.) for 30 minutes at $37^{\circ} \mathrm{C}$ after addition of CDNB and GSH (1 mM final concentrations; Sigma-Aldrich Co.). GST activity was expressed as nM CDNB-GSH conjugates/minute/mg 
protein. The values of enzymatic activities of treated cells were compared with enzymatic activities of untreated cells. Measurements were performed in triplicate and repeated three times. Means \pm SDs were calculated. Statistical significance was ascertained using a Student's $t$-test.

\section{Staining of cellular actin with fluorescent phalloidin}

Cells were grown for 48 hours in 4-chamber glass slides (Becton, Dickinson and Company) and exposed to the NPs or oleic acid for 24 hours. At the end of the treatment, the cell layers were washed in PBS, fixed in 4\% buffered formaldehyde, washed with PBS, permeabilized for 5 minutes in $0.1 \%$ Triton X-100 in PBS, and washed. Then, $200 \mu \mathrm{L}$ of a $1 \%$ BSA (Sigma-Aldrich Co.) and 2.5\% Oregon Green 488 Phalloidin $(6.6 \mu \mathrm{M}$ stock solution in methanol; Thermo Fisher
Scientific) solution in PBS were added. After 20 minutes incubation at room temperature, the cell layers were washed with PBS and $2 \mathrm{~mL}$ of $1 \mu \mathrm{g} / \mathrm{mL} \mathrm{4} 4^{\prime}, 6^{\prime}$-diamidino2-phenylindole (DAPI) (Hoffman-La Roche Ltd., Basel, Switzerland) in PBS was added for 20 minutes. Slides were washed with PBS and mounted in $20 \%$ glycerol in PBS. Fluorescence images were taken with a Zeiss Axioplan 2 Imaging microscope (Carl Zeiss Meditec AG, Jena, Germany) at 400× magnification and $\lambda_{\mathrm{ex}} / \lambda_{\mathrm{em}}=365 / 420 \mathrm{~nm}$ (DAPI) or $\lambda_{\mathrm{ex}} / \lambda_{\mathrm{em}}=$ 450-490/515-565 nm (Oregon Green 488 Phalloidin).

\section{Results \\ Characterization of the NS-USPIO NPs and OA-USPIO NPs}

The determination of the nominal size of NS-USPIO NPs and OA-USPIO NPs was assessed using TEM to confirm

\section{NS-USPIO NPs}

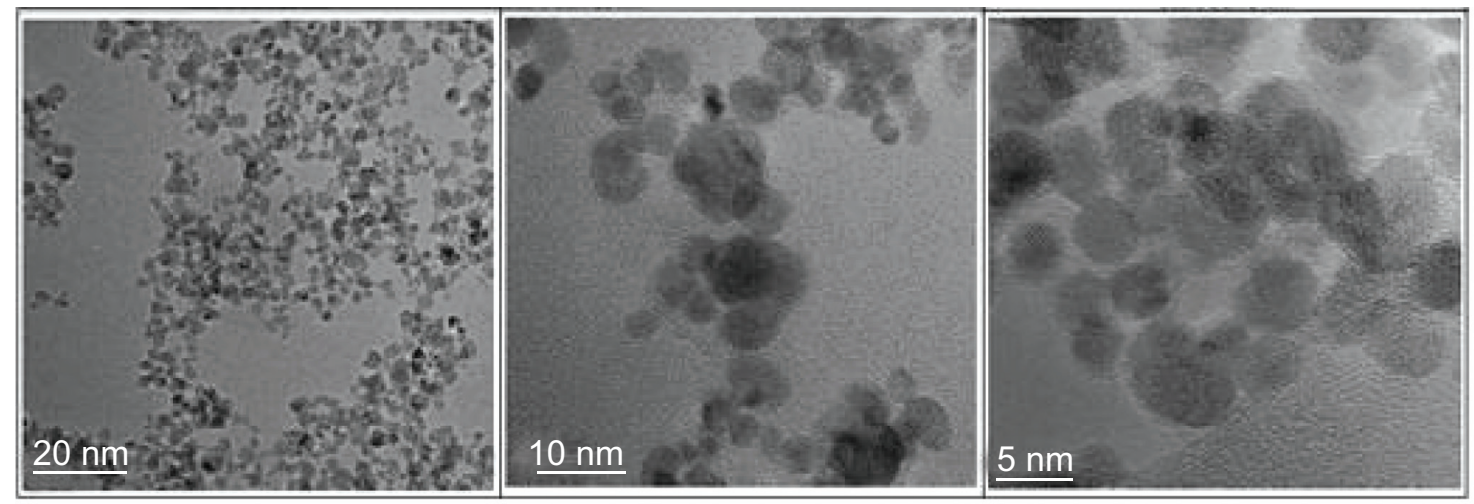

\section{OA-USPIO NPs}

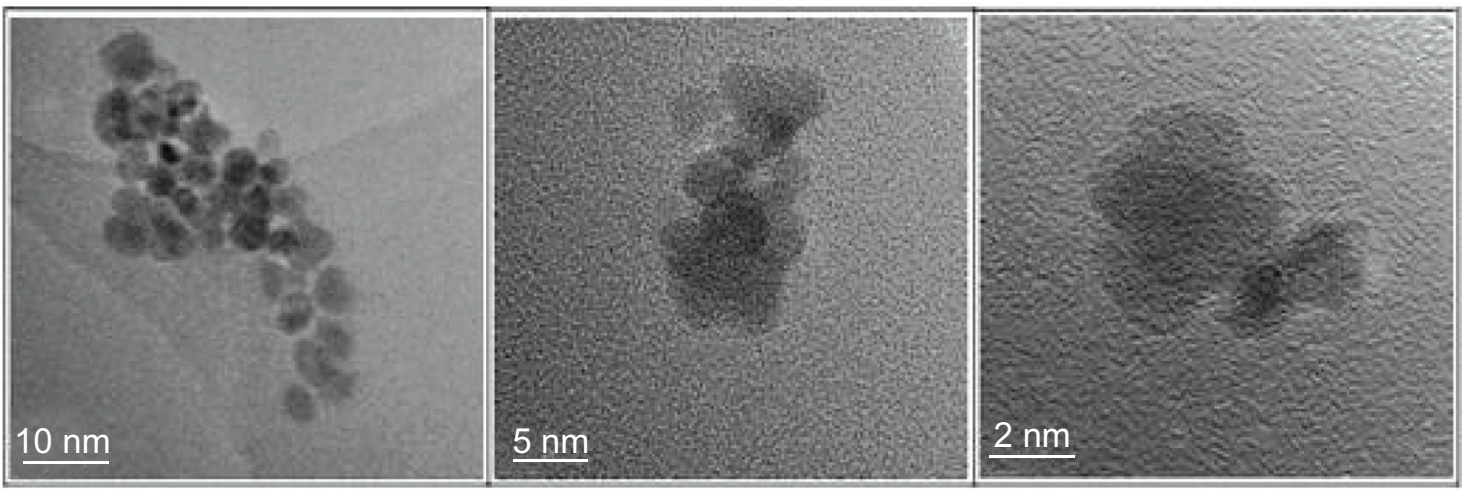

Figure I TEM characterization of the USPIO NPs.

Notes: TEM images of NS-USPIO NPs and OA-USPIO NPs determined in the original solution provided by the provider. Representative TEM images of NS-USPIO NPs (top) at different magnifications (scale bar from left 20, 10, $5 \mathrm{~nm}$ ) and OA-USPIO NPs (bottom) at different magnifications (scale bar from left I0, 5, $2 \mathrm{~nm}$ ). For both samples, crystalline structure and wide size distribution are evident.

Abbreviations: NPs, nanoparticles; NS-USPIO NPs, non-stabilized USPIO NPs; OA-USPIO NPs, oleic-acid-stabilized USPIO NPs; TEM, transmission electron microscopy; USPIO, ultrasmall superparamagnetic iron oxide. 
Table I Size characterization by NTA or DLS of the NS-USPIO NPs and OA-USPIO NPs as a function of the concentration in unconditioned biological media

\begin{tabular}{|c|c|c|c|c|c|c|c|}
\hline & \multirow{2}{*}{$\frac{\text { DI water }}{50 \mu \mathrm{g} / \mathrm{mL}}$} & \multicolumn{3}{|l|}{ FCS } & \multicolumn{3}{|c|}{ DMEM + FCS } \\
\hline & & $25 \mu \mathrm{g} / \mathrm{mL}$ & $50 \mu \mathrm{g} / \mathrm{mL}$ & $100 \mu \mathrm{g} / \mathrm{mL}$ & $25 \mu \mathrm{g} / \mathrm{mL}$ & $50 \mu \mathrm{g} / \mathrm{mL}$ & $100 \mu \mathrm{g} / \mathrm{mL}$ \\
\hline \multicolumn{8}{|l|}{ NS-USPIO NPs } \\
\hline NTA size \pm SD $(\mathrm{nm})$ & $223 \pm 81$ & $338 \pm 303$ & $287 \pm 127$ & $313 \pm 156$ & $197 \pm 150$ & $13 \mid \pm 103$ & $196 \pm 172$ \\
\hline NTA PDI & 0.13 & 0.80 & 0.19 & 0.25 & 0.58 & 0.61 & 0.77 \\
\hline $\mathrm{DLS}$ size $\pm \mathrm{SD}(\mathrm{nm})$ & $236.8 \pm 2.4$ & $38.7 \pm 4.1$ & $64.1 \pm 0.16$ & $116.5 \pm 11.1$ & $2,4 I 5 \pm 235$ & $4,189 \pm 1009$ & $4,087 \pm 1489$ \\
\hline $\mathrm{DLS} P D I \pm S D$ & $0.22 \pm 0.02$ & $0.99 \pm 0.02$ & $\mathrm{I} \pm 0$ & $\mathrm{I} \pm 0$ & $0.47 \pm 0.03$ & $0.20 \pm 0.20$ & $0.59 \pm 0.32$ \\
\hline \multicolumn{8}{|l|}{ OA-USPIO NPs } \\
\hline NTA size \pm SD $(\mathrm{nm})$ & $119 \pm 44$ & $189 \pm 72$ & $176 \pm 77$ & $192 \pm 76$ & $|74 \pm 9|$ & $325 \pm 118$ & $181 \pm 112$ \\
\hline NTA PDI & 0.13 & 0.15 & 0.19 & 0.15 & 0.27 & 0.13 & 0.38 \\
\hline $\mathrm{DLS}$ size $\pm \mathrm{SD}(\mathrm{nm})$ & $110 \pm 0.15$ & $94.1 \pm 7.0$ & II $5.5 \pm 6.1$ & $116.4 \pm 4.6$ & $1,436 \pm 167$ & $2,568 \pm 592$ & $2,525 \pm 240$ \\
\hline DLS PDI $\pm S D$ & $0.17 \pm 0.01$ & $0.55 \pm 0.09$ & $0.48 \pm 0.04$ & $0.47 \pm 0.01$ & $0.95 \pm 0.06$ & $0.5 \mathrm{I} \pm 0.0 \mathrm{I}$ & $0.7 I \pm 0.4 I$ \\
\hline
\end{tabular}

Notes: Means \pm SD of $\mathrm{N}=3$ measurements. FCS: $10 \%$ FCS in PBS. DMEM + FCS: $10 \%$ FCS in DMEM cell culture medium.

Abbreviations: DI, deionized; DLS, dynamic light scattering; DMEM, Dulbecco's Modified Eagle's Medium; FCS, fetal calf serum; NS-USPIO NPs, non-stabilized ultrasmall superparamagnetic iron oxide nanoparticles; NTA, nanoparticle tracking analysis; OA-USPIO NPs, oleic-acid-stabilized ultrasmall superparamagnetic iron oxide nanoparticles; PBS, phosphate-buffered saline; PDI, polydispersity index; SD, standard deviation.

data provided by the supplier. TEM images (Figure 1) highlighted the spherical shape of the particles, their crystalline structures and wide size distribution, and tendency to aggregate under TEM conditions for both samples. No major differences were evident between the NS-USPIO NPs and OA-USPIO NPs from TEM analysis. The average diameter size for both USPIO NPs was measured to be $9.3 \pm 3.5 \mathrm{~nm}$. Higher magnification TEM images also confirmed that the particles were synthesized by physical vapor deposition due to the organized crystalline structure. NS-USPIO NP and OA-USPIO NP characterization was carried out using either DLS to measure NS-USPIO NPs' and OA-USPIO NPs' nominal and hydrodynamic particle size, zeta potential, PDI, and mobility, or NTA (Nanosight
NS500; Malvern Instruments) to measure particle size, PDI, and colloidal and aggregation stabilities at physiologically relevant conditions (Table 1, Table 2, Table S2, Table S3, and Figure 2). The NPs were analyzed first in water, then after incubation for 24 hours into relevant biological matrixes: 10\% FCS in PBS (FCS), DMEM culture medium (DMEM), DMEM culture medium containing 10\% FCS (DMEM + FCS) (Table 1 and Figure 2), or culture medium preconditioned for 72 hours by the $\mathrm{CaCo}_{2}$ and HT29 cells (HT29-CM and $\mathrm{CaCO}_{2}-\mathrm{CM}$ ) (Table 2 and Figure 2). Results were consistent between both DLS and NTA, and between the three NP concentrations analyzed; thus, only NTA results at a NP concentration of $50 \mu \mathrm{g} / \mathrm{mL}$ are shown in Figure 2. From the analysis of the results obtained, it is

Table 2 Size characterization of the NS-USPIO NPs and OA-USPIO NPs as a function of the concentration in colon cell-conditioned media

\begin{tabular}{|c|c|c|c|c|c|c|}
\hline & \multicolumn{3}{|l|}{$\mathrm{CaCo}_{2}-\mathrm{CM}$} & \multicolumn{3}{|l|}{ HT29-CM } \\
\hline & $25 \mu \mathrm{g} / \mathrm{mL}$ & $50 \mu \mathrm{g} / \mathrm{mL}$ & $100 \mu \mathrm{g} / \mathrm{mL}$ & $25 \mu \mathrm{g} / \mathrm{mL}$ & $50 \mu \mathrm{g} / \mathrm{mL}$ & $100 \mu \mathrm{g} / \mathrm{mL}$ \\
\hline \multicolumn{7}{|l|}{ NS-USPIO NPs } \\
\hline NTA size \pm SD $(\mathrm{nm})$ & $254 \pm 103$ & $216 \pm 97$ & $244 \pm 102$ & $285 \pm 103$ & $250 \pm 97$ & $265 \pm 102$ \\
\hline NTA PDI & 0.16 & 0.20 & 0.18 & 0.14 & 0.15 & 0.14 \\
\hline DLS size \pm SD $(\mathrm{nm})$ & $142.4 \pm 2.0$ & $189.2 \pm 1.7$ & $281.7 \pm 50.9$ & $132.8 \pm 5.2$ & $150.5 \pm 0.6$ & $204.2 \pm 7.4$ \\
\hline $\mathrm{DLS} P D I \pm S D$ & $0.60 \pm 0.01$ & $0.50 \pm 0.02$ & $0.50 \pm 0.10$ & $0.40 \pm 0.07$ & $0.26 \pm 0.01$ & $0.3 I \pm 0.04$ \\
\hline \multicolumn{7}{|l|}{ OA-USPIO NPs } \\
\hline NTA size \pm SD $(\mathrm{nm})$ & $179 \pm 783$ & $206 \pm 90$ & $200 \pm 88$ & $188 \pm 78$ & $157 \pm 90$ & $195 \pm 88$ \\
\hline NTA PDI & 0.19 & 0.19 & 0.19 & 0.19 & 0.21 & 0.21 \\
\hline DLS size \pm SD $(\mathrm{nm})$ & $98.9 \pm 3.9$ & $107.8 \pm 5.5$ & $120.2 \pm 1.6$ & $95.0 \pm 1.6$ & $104.0 \pm 20.6$ & $139.2 \pm 5.2$ \\
\hline DLS PDI $\pm S D$ & $0.32 \pm 0.02$ & $0.29 \pm 0.01$ & $0.3 I \pm 0.06$ & $0.28 \pm 0.01$ & $0.24 \pm 0.01$ & $0.34 \pm 0.01$ \\
\hline
\end{tabular}

Notes: Means $\pm \mathrm{SD}$ of $\mathrm{N}=3$ measurements.

Abbreviations: $\mathrm{CaCO}_{2}-\mathrm{CM}$, culture medium conditioned by $\mathrm{CaCo}_{2}$ cells; DLS, dynamic light scattering; HT29-CM, culture medium conditioned by HT29 cells; NSUSPIO NPs, non-stabilized ultrasmall superparamagnetic iron oxide nanoparticles; NTA, nanoparticle tracking analysis; OA-USPIO NPs, oleic-acid-stabilized ultrasmall superparamagnetic iron oxide nanoparticles; PDI, polydispersity index; SD, standard deviation. 
NS-USPIO-NPS

A 4.69

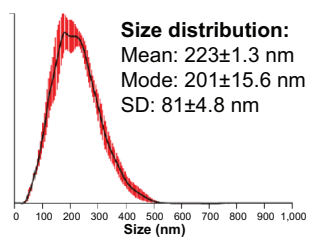

B 1.68

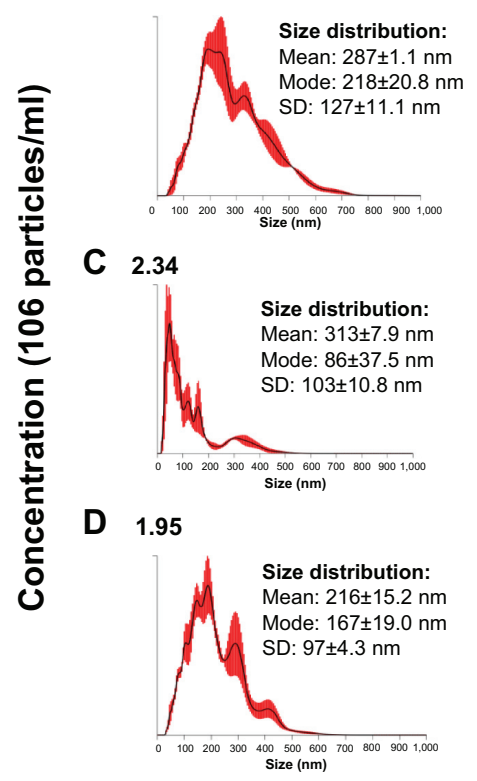

E 3.33

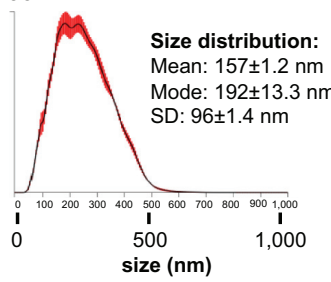

OA-USPIO-NPS

24.21

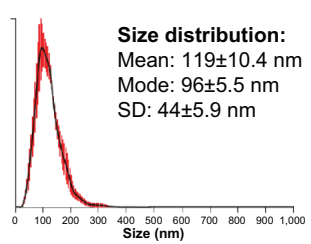

11.76

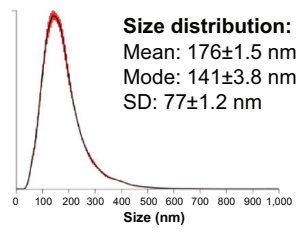

0.73

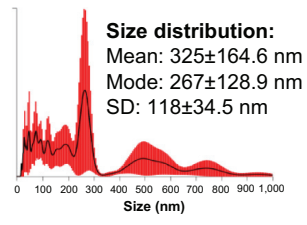

9.44

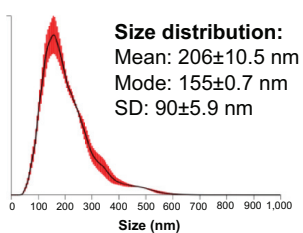

13.41

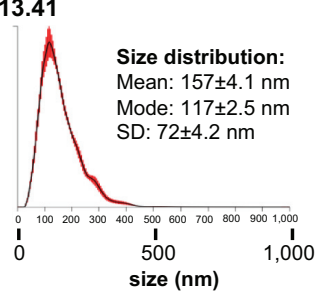

Figure 2 Biophysical characteristics of NS-USPIO NPs and OA-USPIO NPs in dispersion media.

Notes: NTA batch analysis plots of the two types of USPIO NPs and information are provided; all data presented: $50 \mu \mathrm{g} / \mathrm{mL}$ and $\mathrm{N}=3$; red: variance between measurements within the batches analyzed. Data represent batch averaged size/ concentration results. Red error bars indicate $\pm \mathrm{I}$ standard error of the mean Detail of sample analyzed in their solutions at $\mathrm{pH}=7$ : (A): filtered ultrapure deionized water; (B): DMEM + 10\% FCS; (C): DMEM only; (D): $\mathrm{CaCo}_{2}-\mathrm{CM}$; (E) HT29-CM.

Abbreviations: $\mathrm{CaCo}_{2}-\mathrm{CM}$, culture medium conditioned by $\mathrm{CaCo}_{2}$ cells; DMEM, Dulbecco's Modified Eagle's Medium; FCS, fetal calf serum; HT29-CM, culture medium conditioned by HT29 cells; NPs, nanoparticles; NS-USPIO NPs, non-stabilized USPIO NPs; NTA, nanoparticle tracking analysis; OA-USPIO NPs, oleic-acidstabilized USPIO NPs; SD, standard deviation; USPIO, ultrasmall superparamagnetic iron oxide.

interesting to point out the differences and similarities of aggregation behavior, stability, and PDI of the NS-USPIO NPs and OA-USPIO NPs between the different solutions used in this work. The USPIO NPs response was highly dispersion-medium-dependent. OA-USPIO NPs displayed a narrower size distribution in water and FCS than NS-USPIO
NPs, whereas NS-USPIO NPs showed less aggregation in DMEM + FCS than OA-USPIO NPs. In both HT29-CM and $\mathrm{CaCo}_{2}-\mathrm{CM}$, OA-USPIO NPs showed less aggregation than USPIO NPs, but aggregation recovery after incubation. Thus, after 24 hours incubation in the cell culture medium conditioned by the $\mathrm{CaCo}_{2}$ and HT29 cells, both USPIO NPs were undergoing a stabilization response as shown by the values reported in Table 2 and also shown by the NTA batch analysis particle size plots reported in Figure 2. The zeta potentials of both USPIO NPs could not be determined in the biological matrices, since the NPs agglomerate. The zeta potentials are provided only for the nanosized NPs contained in the agglomerates in Table S2A and Table S2B; these values are in parentheses to underline this uncertainty.

\section{Uptake and cytotoxicity of the NS-USPIO NPs and OA-USPIO NPs}

In cells exposed to NS-USPIO NPs, the NPs were mostly cell-associated after 24 hours of exposure (Figure 3A) as determined by the quantitative Prussian Blue reaction of iron, whereas the level of cell-associated iron was much lower in cells exposed to OA-USPIO NPs, close to the detection limit of the Prussian Blue reaction, but still detectable (Figure 3B). None of the USPIO NPs were cytotoxic for the colon cells (Figure 4A). The cytotoxicity of oleic acid for the human colon cells was also evaluated. In a $50 \mu \mathrm{g}$ iron/mL OA-USPIO NPs solution, the concentration of oleic acid was $23 \mu \mathrm{M}$, which represents the maximal oleic acid concentration achieved in our experiments; thus, we evaluated the cytotoxicity of multiples of this initial concentration. While a ten-fold-concentration of oleic acid had no effect on the viability of the human colon cells, only the 100- and 1,000-fold-concentrations dramatically decreased cell survival (Figure 4B). Ethanol, the solvent of oleic acid, at the highest concentration achieved in our experiments, had no effect on cell survival. Thus, neither the oleic acid stabilizer of the OA-USPIO NPs nor the two USPIO NPs were cytotoxic for the cells.

\section{Cell stress responses to exposure to the NS-USPIO NPs and OA-USPIO NPs}

Upon exposure of the human colon cells to NS-USPIO NPs, OA-USPIO NPs, or free oleic acid for 24 hours, no effects were observed on the localization and expression of actin cytoskeleton in both colon cells as determined by histological staining with fluorescent phalloidin (Figure 5, $\mathrm{CaCo}_{2}$ cells, results not shown for HT29 cells). The expression of proteins 
A

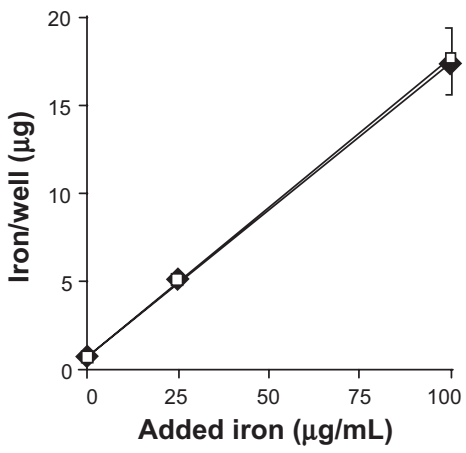

B

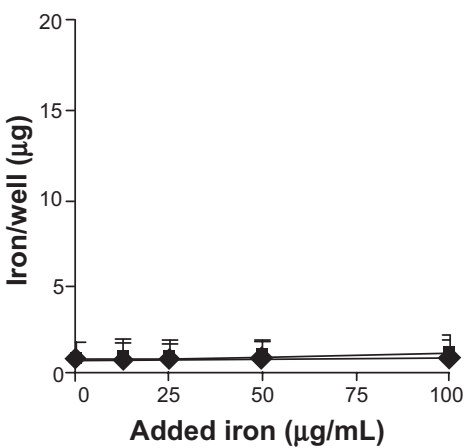

Figure 3 Uptake of NS-USPIO NPs and OA-USPIO NPs by human colon cancer cells.

Notes: Human colon cancer cells were exposed to increasing concentrations of NS-USPIO NPs (A) or OA-USPIO NPs (B) for 24 hours, then cell-associated iron per well was determined with the Prussian Blue assay. Results are the means \pm SD of the triplicate of two independent experiments. : $\mathrm{HT29}$ cells; $\square$ : CaCo ${ }_{2}$ cells.

Abbreviations: NPs, nanoparticles; NS-USPIO NPs, non-stabilized USPIO NPs; OA-USPIO NPs, oleic-acid-stabilized USPIO NPs; SD, standard deviation; USPIO, ultrasmall superparamagnetic iron oxide.
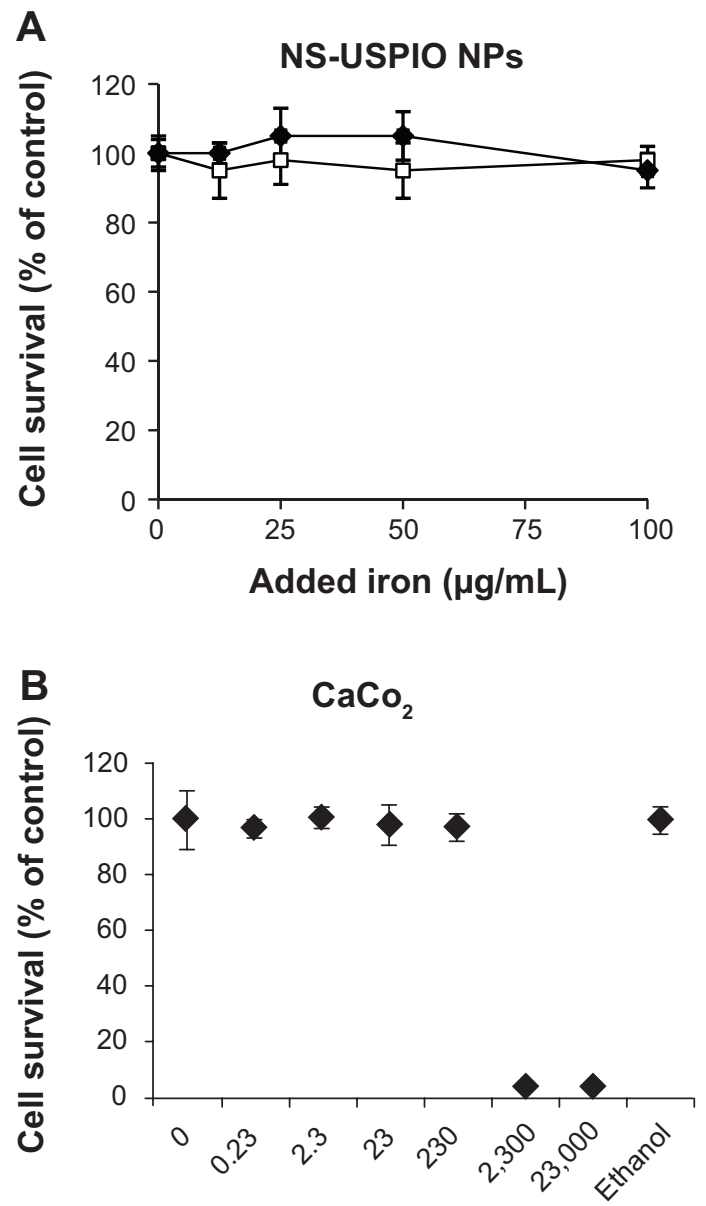

Oleic acid $(\mu \mathrm{M})$

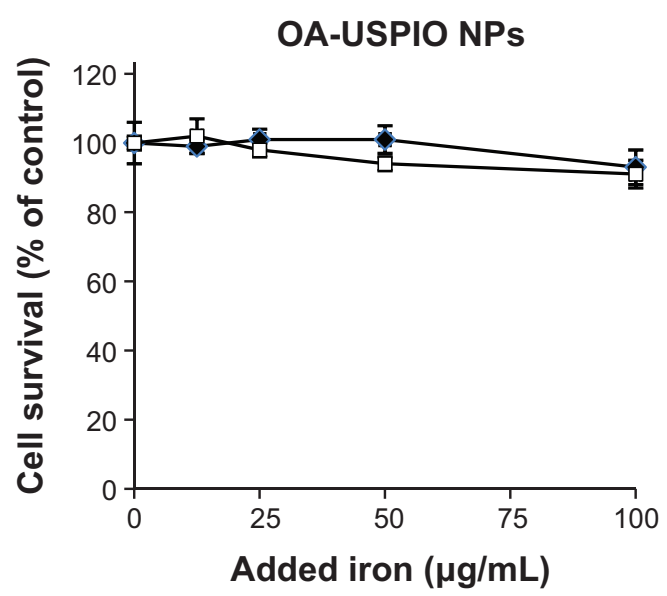

HT29

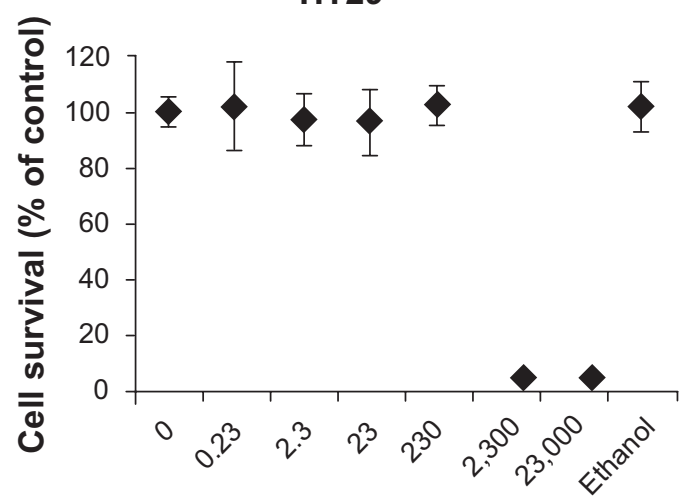

Oleic acid $(\mu \mathrm{M})$

Figure 4 Cytotoxicity of NS-USPIO NPs, OA-USPIO NPs, and free oleic acid for human colon cells.

Notes: (A) Cytotoxicity of NS-USPIO NPs and OA-USPIO NPs. $\mathrm{CaCO}_{2}$ and HT29 cells were exposed for 24 hours to increasing amounts of NS-USPIO NPs or OA-USPIO NPs, then the cell metabolic activity was determined using an MTT assay. Cytotoxicity is expressed as the percentage of cell survival of exposed cells compared to unexposed cells. Means \pm SD were calculated. $\square: \mathrm{CaCo}_{2}$ cells; $\bullet: \mathrm{HT} 29$ cells. (B) Cytotoxicity of free oleic acid. Human $\mathrm{HT}_{2} 9$ and $\mathrm{CaCo}_{2}$ cells were exposed for 72 hours to increasing concentrations of oleic acid or to the highest concentration (1.75\%) of ethanol used to dissolve oleic acid, then an MTT test was performed. Results are expressed as the percentage of cell survival of exposed cells compared to unexposed cells and are the means \pm SD of triplicates of two independent experiments. Statistical significance was assessed using a Student's t-test.

Abbreviations: MTT, 3-(4,5-dimethyl-2-thiazoyl)-2,5-diphenyltetrazolium bromide; NPs, nanoparticles; NS-USPIO NPs, non-stabilized USPIO NPs; OA-USPIO NPs, oleicacid-stabilized USPIO NPs; SD, standard deviation; USPIO, ultrasmall superparamagnetic iron oxide. 

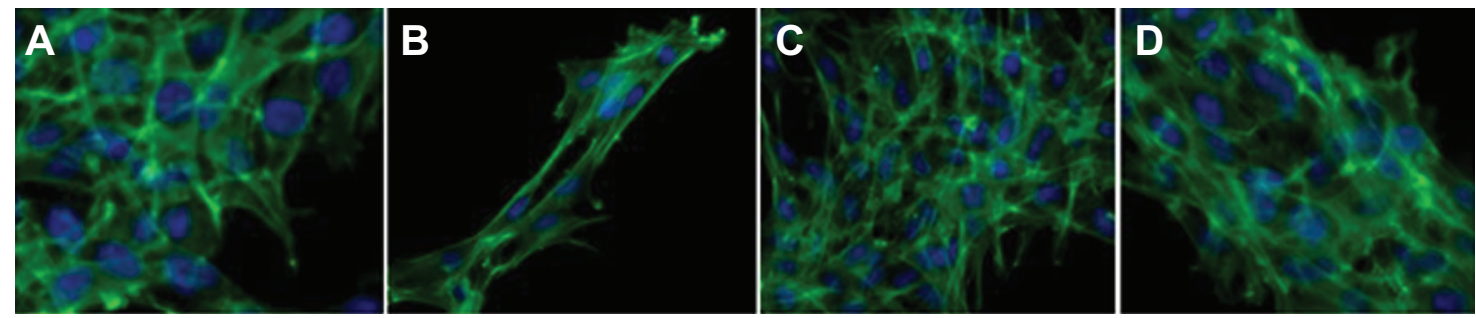

Figure 5 Cellular actin in cells exposed to NS-USPIO NPs, OA-USPIO NPs, or free OA.

Notes: $\mathrm{CaCO}_{2}$ cells were grown for 48 hours in four-chamber glass slides then either unexposed (A) or exposed to NS-USPIO NPs (B), OA-USPIO NPs (C), or free OA (D) for 24 hours. At the end of the treatment, the cell layers were analyzed with Oregon Green 488 Phalloidin to label cytoskeletal actin (green) and DAPI to label nuclei (blue) under a fluorescence microscope. Control: unexposed cells.

Abbreviations: DAPI, 4',6'-diamidino-2-phenylindole; NPs, nanoparticles; NS-USPIO NPs, non-stabilized USPIO NPs; OA, oleic acid; OA-USPIO NPs, oleic-acid-stabilized USPIO NPs; USPIO, ultrasmall superparamagnetic iron oxide.

involved in other cellular responses was assessed using Western blotting experiments (Figure 6A and Figure 6B).

The expression and/or activation state of markers of apoptosis (cleaved poly [ADP-ribose] polymerase [PARP]), double-strand DNA damage (phosphorylated histone H2AX $[\gamma \mathrm{H} 2 \mathrm{AX}]$ ), oxidative stress (the GST- $\pi$ ), as well as the enzymatic activity of GST (results not shown), or hypoxia (hypoxia-inducible factor $1-\alpha[\mathrm{HIF}-1 \alpha]$ ) were not affected by the exposure of colon cells to NS-USPIO NPs, OA-USPIO NPs, or free oleic acid. A weak increase of the expression of the lysosomal protease procathepsin D and cathepsin D was observed in $\mathrm{CaCo}_{2}$ cells treated with NS-USPIO NPs, and a clear increase in the expression of the autophagic marker LC3I/ II was shown in $\mathrm{CaCo}_{2}$ cells exposed to both NS-USPIO NPs and OA-USPIO NPs, but not in cells exposed to free oleic acid. The transferrin receptor-1/CD71, an iron transporter regulated by intracellular iron, was only expressed by HT29 cells and its expression slightly decreased when the cells were exposed to NS-USPIO NPs, which are internalized at high levels by the cells. Of the three heat shock protein (HSP) chaperones evaluated, only the expression of HSP90 significantly increased in $\mathrm{CaCo}_{2}$ cells, but not in HT29 cells, exposed to NS-USPIO NPs and increased at an even higher level in those cells exposed to OA-USPIO NPs. Thus cell-selective and NP-selective effects of USPIO NPs in the lysosomal, iron transport, and autophagic responses of colon cells, and a stress response mediated by the chaperone HSP90 were demonstrated.

\section{OA-USPIO-NPs-induced formation of lipid vacuoles by colon cells}

Then we evaluated the effect of oleic acid, either free or USPIO-NPs-associated, on the metabolism and handling of lipids in the human colon cells. Both NS-USPIO NPs and OA-USPIO NPs, but not free oleic acid, decreased the incorporation of acetate in $\mathrm{CaCo}_{2}$ cells, but not in
HT29 cells (Figure 7). OA-USPIO NPs decreased acetate incorporation significantly more than NS-USPIO NPs, suggesting a selective interference with lipid metabolism in these cells. Therefore, we examined the effects of NSUSPIO NPs, OA-USPIO NPs, and free oleic acid on the aspect of cells when examined under light microscopy (Figure 8). In cells exposed to NS-USPIO NPs, high amounts of the iron oxide cores of NPs could be seen inside cells in the TEM images (Figure 8, black arrows), while only low amounts of the iron oxide cores could be detected by TEM in cells exposed to OA-USPIO NPs, which are internalized at much lower levels than NS-USPIO NPs. However, TEM images demonstrated the presence of a high amount of vacuoles in cells exposed to OA-USPIO NPs, and of a much lower amount of vacuoles in cells exposed to free oleic acid (Figure 8, white arrows). The lipidic nature of these vacuoles was demonstrated by histological staining with Oil-Red-O, a fat-soluble red-colored dye which allows visualizing and evaluating lipids in cells (Figure 9). In cells exposed to OA-USPIO NPs, many red-colored vacuoles were observed, while in cells exposed to an equimolar concentration of free oleic acid achieved in OA-USPIO NPs, only rare lipid vacuoles were observed. Thus, the Oil-Red-O histological staining strongly supported a lipidic nature for the vacuoles observed in TEM images. Thus the OA-USPIO NPs, despite their poor cellular uptake, were inducing a cell reaction suggesting an effect of the oleic acid stabilizer in the cell metabolism.

As shown by TEM, the appearance of the lipid in cells exposed to OA-USPIO NPs was time-dependent (Figure 10A, white arrows). In order to validate the TEM observations, the diameter and the number of lipid droplets/vacuoles per cell were determined on TEM images of at least 20 different cells per treatment randomly selected from cultures of HT29 and $\mathrm{CaCo}_{2}$ cells exposed to OA-USPIO NPs or free oleic acid, 
A

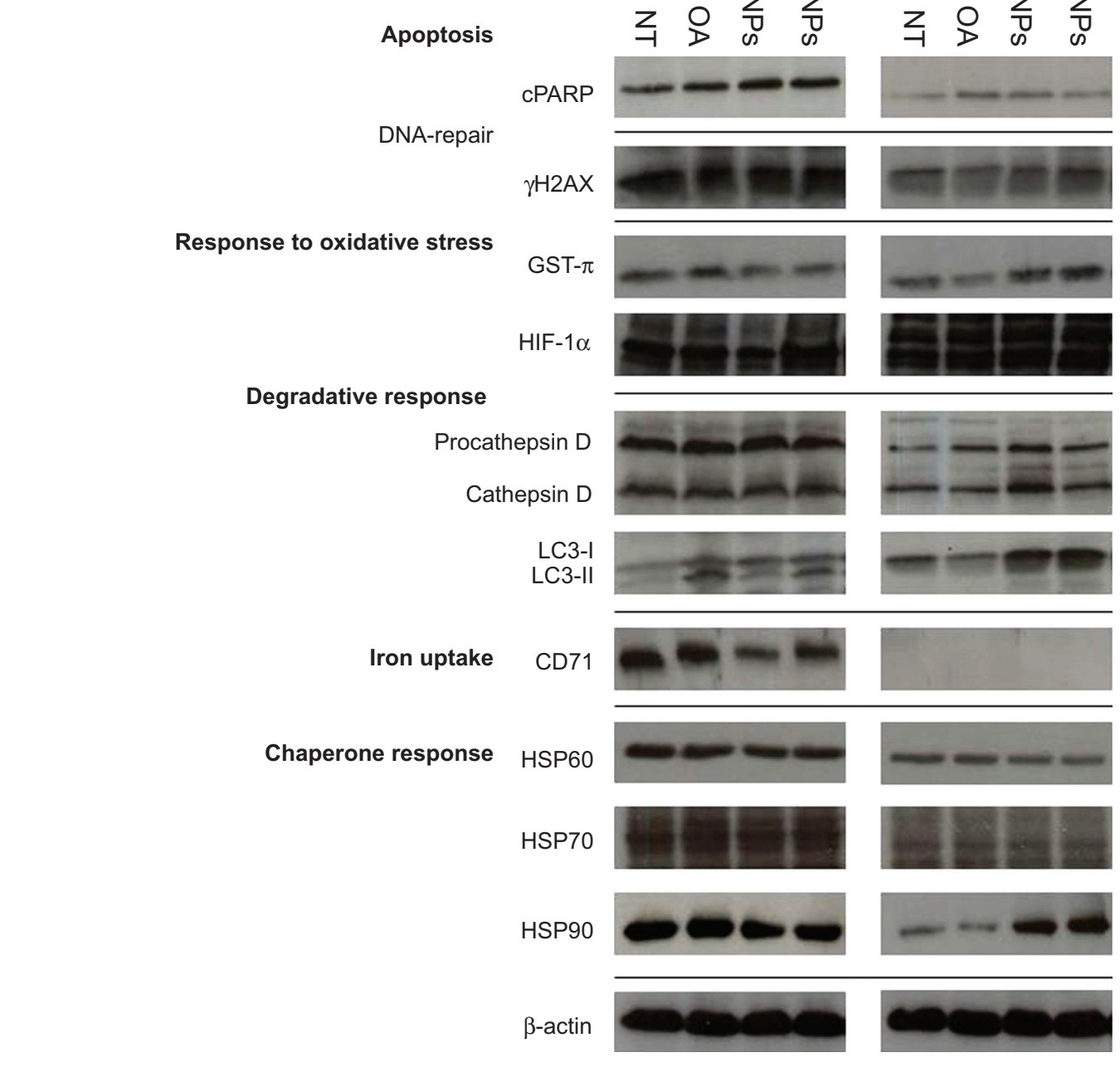

HT29 $\mathrm{CaCo}_{2}$

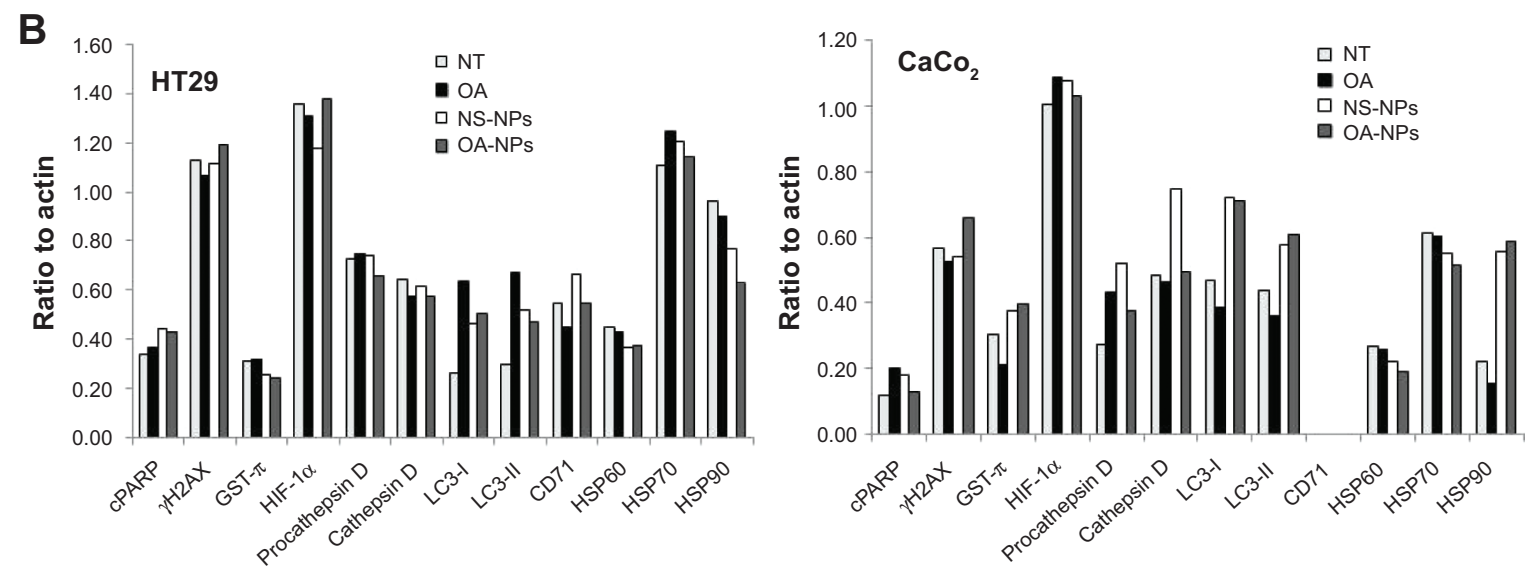

Figure 6 Cellular stress responses to exposure to free OA, NS-USPIO NPs, or OA-USPIO NPs.

Notes: $\mathrm{HT} 29$ and $\mathrm{CaCo}_{2}$ cells were exposed for 24 hours to either $23 \mu \mathrm{M}$ free OA, NS-USPIO NPs (50 $\mu \mathrm{g}$ iron/mL), or OA-USPIO NPs (50 $\mu \mathrm{g}$ iron/mL), then the expression of proteins involved in DNA repair, apoptosis, oxidative stress response, lysosomal and autophagic activation (degradative response), iron uptake, or heat shock chaperone induction was analyzed by Western blotting (A), then the ratio of the band intensities of each protein to the band intensity of actin was evaluated (B).

Abbreviations: CD7I, transferrin receptor; cPARP, cleaved poly(ADP-ribose) polymerase; GST- $\pi$, glutathione S-transferase- $\pi$; $\gamma H 2 A X$, phospho-histone H2AX; HIF-I $\alpha$, hypoxia-inducible factor I- $\alpha$; HSP, heat shock protein; NPs, nanoparticles; NS-NPs, NS-USPIO NPs; NS-USPIO NPs, non-stabilized USPIO NPs; NT, non-treated; OA, oleic acid; OA-NPs, OA-USPIO NPs; OA-USPIO NPs, oleic-acid-stabilized USPIO NPs; USPIO, ultrasmall superparamagnetic iron oxide. 
A

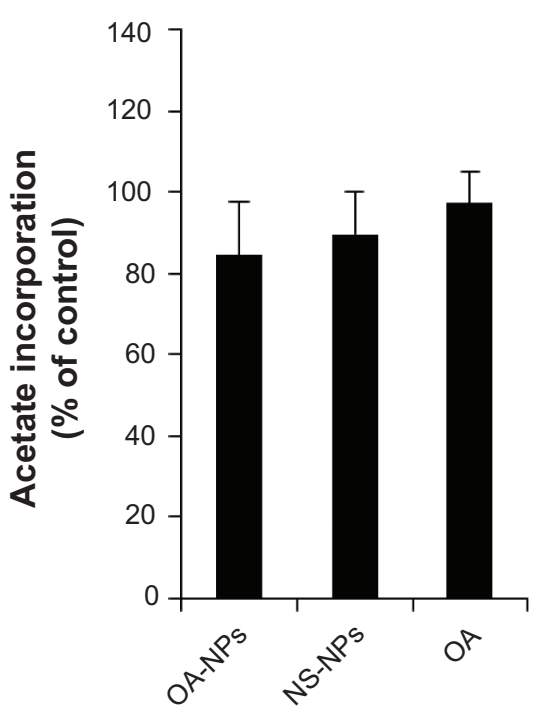

B

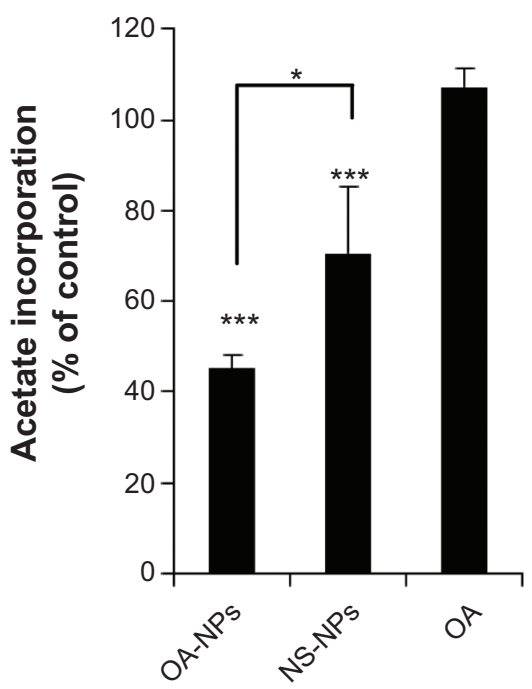

Figure 7 OA-USPIO NPs and NS-USPIO NPs, but not free oleic acid, inhibit lipid synthesis in human colon cells.

Notes: $\mathrm{HT} 29$ cells $(\mathbf{A})$ or $\mathrm{CaCo}_{2}$ cells (B) were exposed to NS-USPIO NPs, OA-USPIO NPs (50 $\mu \mathrm{g}$ iron/mL), or free OA ( $\left.23 \mu \mathrm{M}\right)$ for 24 hours, then the synthesis of lipids by the cells was determined by the incorporation of $\left[{ }^{14} \mathrm{C}\right]$ sodium acetate (acetate). Results are expressed as percentage of acetate incorporation in exposed cells compared to unexposed cells and are the means \pm SD of the triplicate of two independent experiments. Statistical significance was assessed using a Student's $t$-test. $* P<0.05$; $* * * P<0.001$. Abbreviations: NPs, nanoparticles; NS-NPs, NS-USPIO NPs; NS-USPIO NPs, non-stabilized USPIO NPs; OA, oleic acid; OA-NPs, OA-USPIO NPs; OA-USPIO NPs, oleicacid-stabilized USPIO NPs; SD, standard deviation; USPIO, ultrasmall superparamagnetic iron oxide.

after 6 hours and 24 hours of cell exposure (Figure 10B). In both colon cancer cell lines, the number and the diameter of the vacuoles significantly increased after exposure to OAUSPIO NPs in comparison to cells exposed to free oleic acid or in control cells.

\section{Discussion}

Magnetic USPIO NPs are in clinical use or under evaluation as diagnostic, therapeutic, and theranostic agents, which include contrast agents for magnetic resonance imaging, targeted drug delivery, cell sorting and tracking, or hyperthermia. With these expanding applications, the potential toxicity/cytotoxicity of magnetic NPs is of concern and is under experimental evaluation. Therefore, in the present manuscript we compared the responses of two human colon epithelial cancer cells (HT29 and $\mathrm{CaCO}_{2}$ cells) to exposure to two USPIO NPs with the same core nominal size and morphology, but either NSUSPIO NPs or OA-USPIO NPs, as well as the free oleic acid which was used as the stabilizing acid of the USPIO NPs.
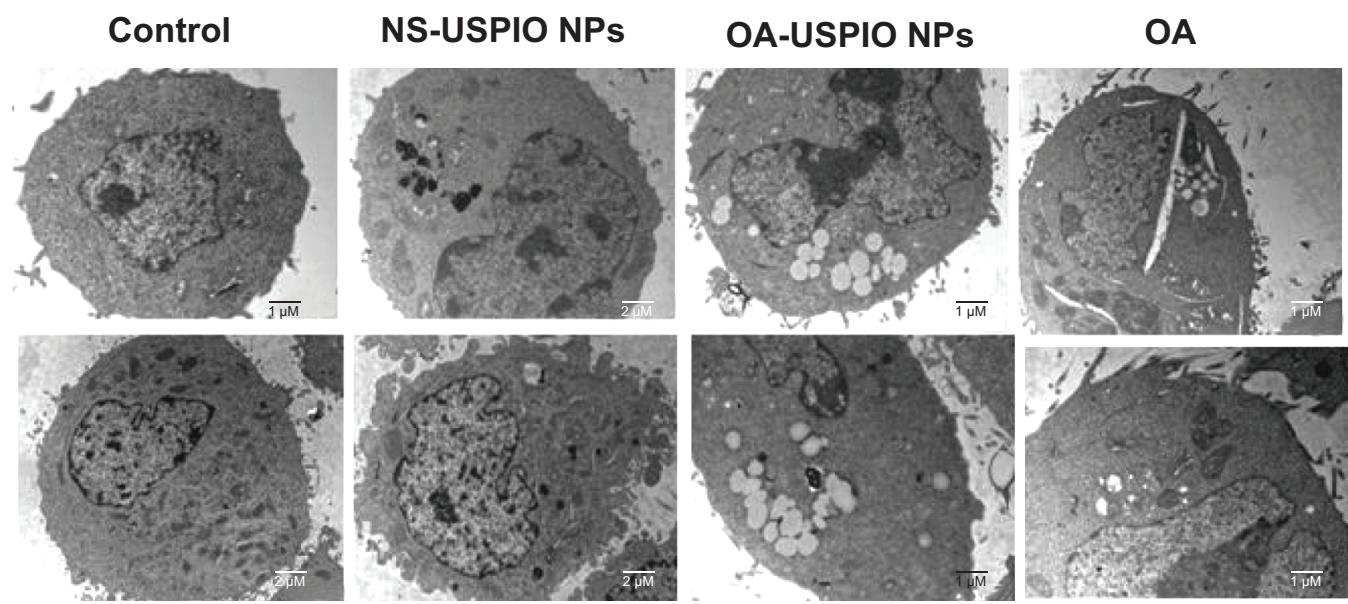

HT29
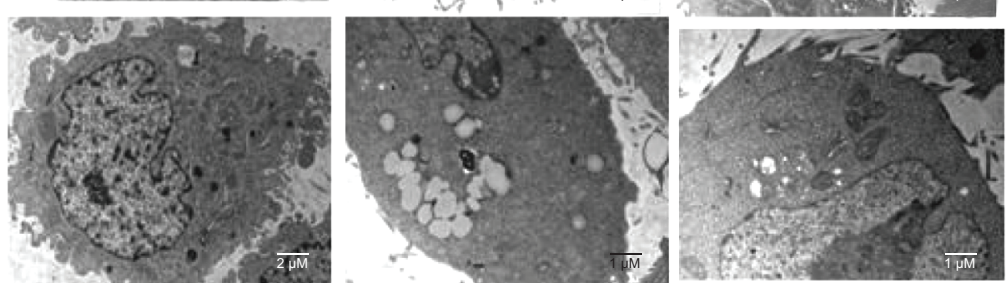

$\mathrm{CaCO}_{2}$

Figure 8 Induction of vacuoles in human colon cancer cells exposed to OA-USPIO NPs or free OA.

Notes: Human $\mathrm{HT} 29$ or $\mathrm{CaCo}_{2}$ colon cancer cells were either unexposed (control) or exposed to NS-USPIO NPs or OA-USPIO NPs $(50 \mu \mathrm{g}$ iron/mL), or free OA (23 $\mu$ M) for 24 hours, then TEM images were acquired. Black arrows: iron oxide cores; white arrows: vacuoles.

Abbreviations: NPs, nanoparticles; NS-USPIO NPs, non-stabilized USPIO NPs; OA, oleic acid; OA-USPIO NPs, oleic-acid-stabilized USPIO NPs; USPIO, ultrasmall superparamagnetic iron oxide; TEM, transmission electron microscopy. 

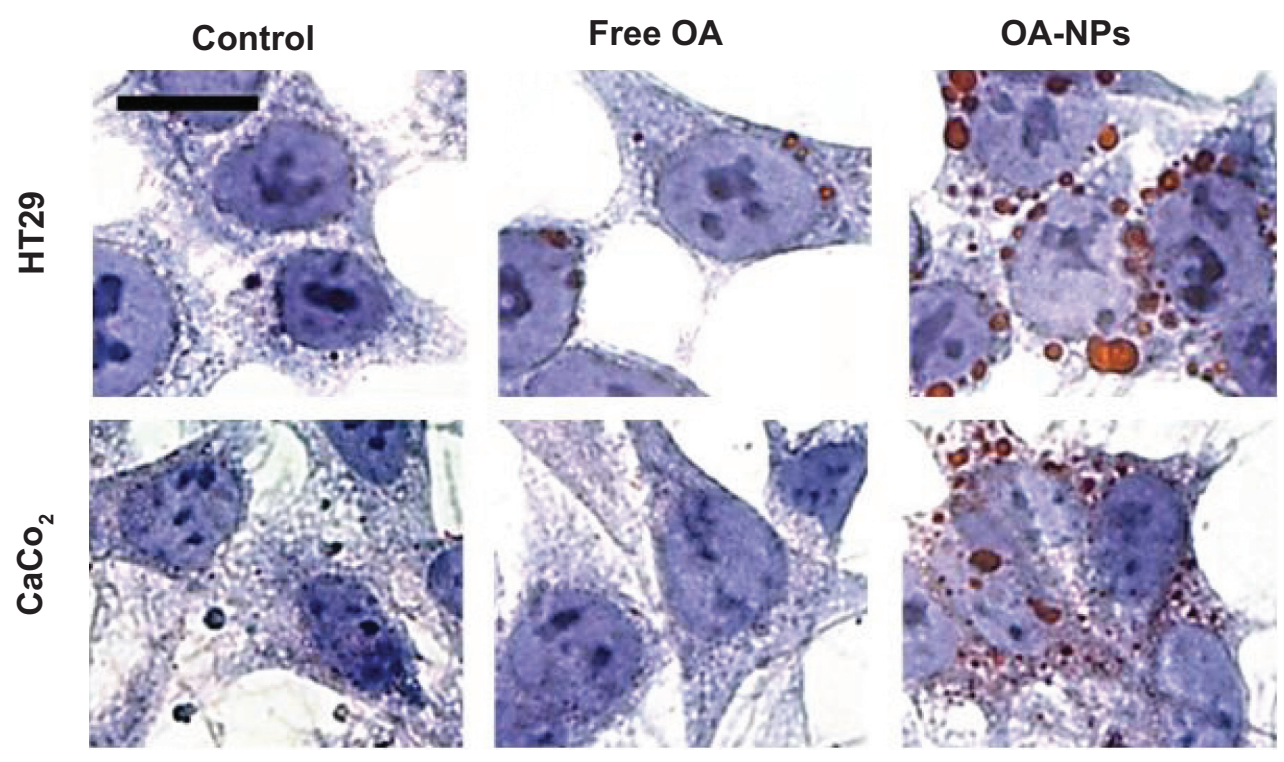

Figure 9 Induction of lipid droplets/vacuoles by free OA or OA-USPIO NPs in human colon cells.

Notes: $\mathrm{CaCO}_{2}$ cells or HT29 cells were unexposed (control) or exposed to either free OA (OA, $\left.23 \mu \mathrm{M}\right)$ or OA-USPIO NPs (50 $\mu$ g iron/mL) for 24 hours, then fixed, stained with Oil-Red-O (red) and counterstained with hematoxylin (blue). Bar: $20 \mu \mathrm{m}$

Abbreviations: NPs, nanoparticles; OA, oleic acid; OA-NPs, OA-USPIO NPs; OA-USPIO NPs, oleic-acid-stabilized USPIO NPs; USPIO, ultrasmall superparamagnetic iron oxide.

First, the two USPIO NPs were characterized in detail for their biophysical characteristics in several relevant biomedical cell culture media, including cell culture media unconditioned or preconditioned by the cells studied (HT29-CM or $\mathrm{CaCo}_{2}-\mathrm{CM}$ ). The determination by TEM of the shape, size distribution, and average diameter of the iron oxide core were similar for both USPIO NPs. The detailed physicochemical properties of NS-USPIO NPs and OA-USPIO NPs were also assessed using DLS and NTA in the different biological media. The incremental characterization from water to FCS, to DMEM only, then to DMEM + FCS, and finally to cell-CM was carried out to systematically dissect each single aspect of the NP suspension in biological media to understand how the components making the media induced aggregation. The physicochemical characterization of the NS-USPIO NPs showed very different behavior than that of the OA-USPIO NPs. OA-USPIO NPs displayed a narrower size distribution in water and FCS than NS-USPIO NPs. In the presence of FCS, NS-USPIO NPs were initially highly aggregating but tended to better stabilize, showing less aggregation in DMEM + FCS over the long-term than OA-USPIO NPs. In both HT29-CM and $\mathrm{CaCo}_{2}-\mathrm{CM}$, OA-USPIO NPs showed less aggregation than NS-USPIO NPs, but aggregation recovery after incubation in the cell-CM. The surface characteristics, size, agglomeration state, and chemical composition are important factors to be considered for the reaction of cells to the stress of being exposed to NPs.
Thus, after incubation in the cell culture medium conditioned by the $\mathrm{CaCo}_{2}$ and HT29 cells, OA-USPIO NPs underwent a stabilization response, suggesting a different mechanical interaction between the particles and the cells in their culture medium. Different surface properties of NPs attract specific molecules from the surrounding medium, especially proteins, thus forming different protein corona. ${ }^{17}$ Thus, we can hypothesize that the protein corona of USPIO NPs in cell-CM is responsible for their improved dispersibility.

The factors to be considered for the reaction of cells to the stress of being exposed to NPs are multiple. The state of aggregation/agglomeration of NPs is an important feature that influences the cell responses to NPs. For example, cytotoxicity and genotoxicity of $\mathrm{TiO}_{2} \mathrm{NPs}$ were dependent on the state of the NPs aggregation. ${ }^{18}$ Unstabilized NPs tend to agglomerate, while stabilized NPs are more dispersed. ${ }^{19}$ Also, the chemical composition of the surface coating of the NPs is another relevant factor. The coating surface of silver NPs determined cytotoxicity. ${ }^{20}$ For example, the oleate coating of nickel ferrite NPs decreased cell viability compared with uncoated NPs. ${ }^{21}$ Oleate-coated ZnO NPs induced micronuclei, whereas uncoated ZnO NPs were not genotoxic. ${ }^{22}$ Here, we showed that the state of USPIO NPs agglomeration was important for their uptake by the human colon cells but not for their cytotoxicity for the cells. However, the size of the NPs is not the only reason for the low uptake of OA-USPIO NPs; the negative charges at their surface can be hypothesized 
A

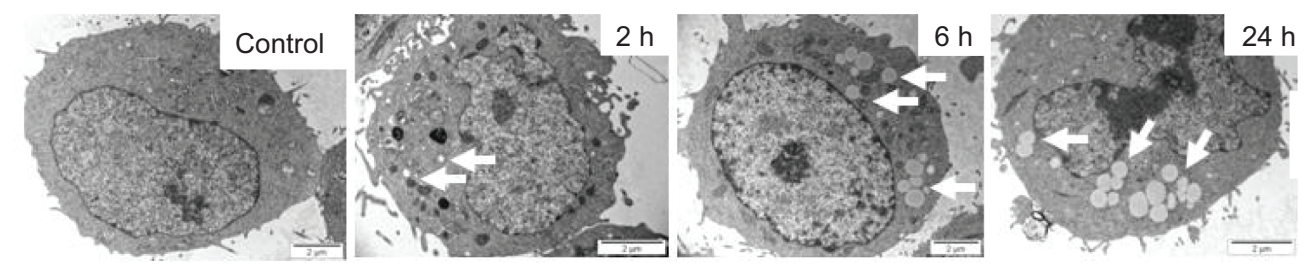

HT29
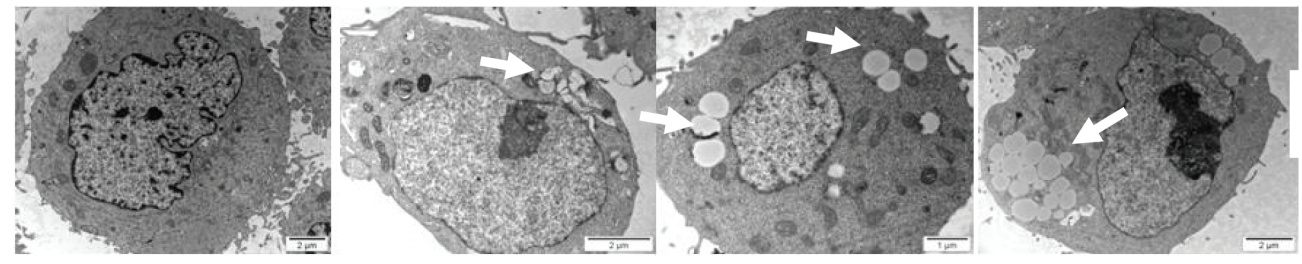

\section{$\mathrm{CaCO}_{2}$}

B
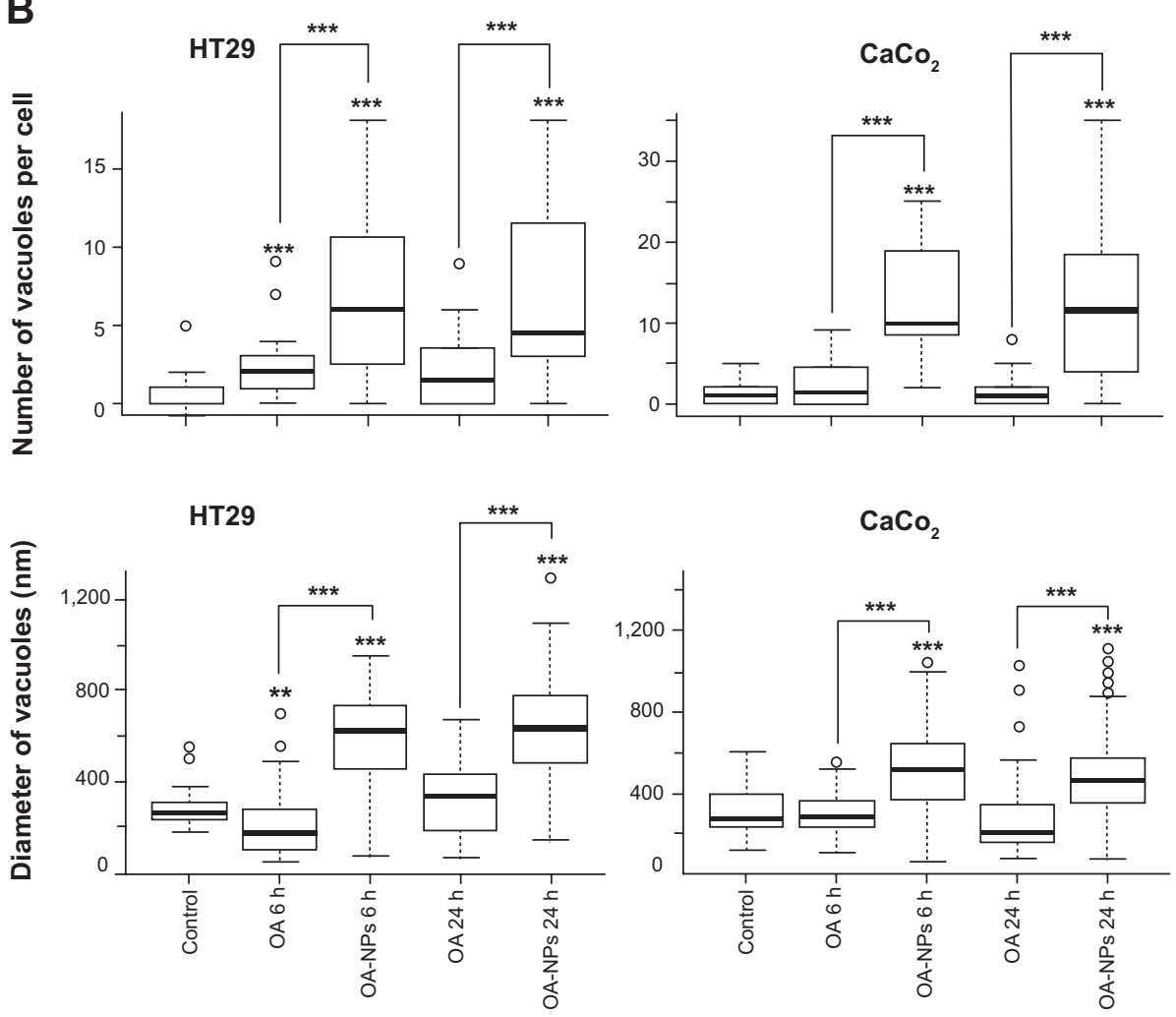

Figure 10 Evaluation of the formation of lipid vacuoles/droplets in colon cells.

Notes: (A) Human HT29 or $\mathrm{CaCo}_{2}$ colon cancer cells were exposed to OA-USPIO NPs (50 $\mu \mathrm{g}$ iron/mL). TEM images were acquired after 0 h, 2 h, $6 \mathrm{~h}$, or $24 \mathrm{~h}$ exposure. White arrows: lipid vacuoles; scale bar $=2 \mu \mathrm{m}$. The white arrows indicate vacuoles/droplets. (B) Human $\mathrm{HT} 29$ or $\mathrm{CaCo}_{2}$ colon cancer cells were unexposed (control) or exposed to OA-USPIO NPs $(50 \mu \mathrm{g}$ iron/mL) or free OA $(23 \mu \mathrm{M})$ for $6 \mathrm{~h}$ or $24 \mathrm{~h}$, then TEM images of the cells (at least 20 cells per treatment) were acquired and the statistical evaluation of the number and diameter of the vacuoles per cell was performed. Statistical significance was assessed using the Wilcoxon-Mann-Whitney test: $* * P<0.0$; $* * * P<0.00$ I. Black bar: median, $\circ$ : outliers. Control: cells exposed only to culture medium.

Abbreviations: h, hours; NPs, nanoparticles; OA, oleic acid; OA-NPs, OA-USPIO NPs; OA-USPIO NPs, oleic-acid-stabilized USPIO NPs; USPIO, ultrasmall superparamagnetic iron oxide; TEM, transmission electron microscopy.

to be also responsible of this low cell uptake. Using many different cells and USPIO NPs coated with various polyvinyl alcohols (PVAs), we have previously shown ${ }^{8,12}$ that USPIO NPs coated with native or carboxyl-modified PVAs were not taken up at high levels by the cells, while amino-PVA-coated or uncoated USPIO NPs were easily and at high levels taken up by the cells, suggesting a determining role for positive charges in the cell uptake of these NPs.

The expression and/or activation state of proteins involved in specific cellular responses of the two human colon cells was also assessed. The surface properties of the USPIO NPs and the level of NP uptake by the cells 
influenced their metabolic response. We did not observe a modification of cytoskeletal actin in cells exposed to either of the USPIO NPs. PARP is involved in DNA repair and is inactivated by caspase cleavage in apoptosis, and the histone $\mathrm{H} 2 \mathrm{AX}(\gamma \mathrm{H} 2 \mathrm{AX})$ is phosphorylated in response to DNA damage. ${ }^{23,24}$ The GST- $\pi$ is regulated by the HIF- $1 \alpha$, by a hypoxic stress and the level of cell iron. ${ }^{16,25}$ Neither of the USPIO NPs modified the PARP, $\gamma \mathrm{H} 2 \mathrm{AX}$, GST- $\pi$, or HIF-1 $\alpha$. The transferrin receptor protein-1/CD71, an iron transporter, is downregulated by high concentrations of intracellular iron. ${ }^{26}$ The transferrin receptor protein-1/ CD71 expression slightly decreased in HT29 cells exposed to NS-USPIO NPs, which are internalized at high levels by the cells, but not in cells exposed to OA-USPIO NPs, which are internalized at much lower levels. We have previously shown a comparable effect in human melanoma and endothelial cells using cationic USPIO NPs, which are highly taken up by human cells. ${ }^{27,28}$ A cell autophagic response to NP exposure will result in the activation of lysosomal proteases and an increase in the expression of the autophagic marker LC3I/II. ${ }^{29}$ A weak increase of the expression of the lysosomal protease procathepsin D and cathepsin D was observed in $\mathrm{CaCo}_{2}$ cells exposed to NS-USPIO NPs, but not to OAUSPIO NPs, suggesting that the level of intracellular iron is responsible for the cathepsin D as well as CD71 responses. We have previously shown in human endothelial cells an autophagic response to the highly internalized cationic amino-PVA-USPIO NPs. ${ }^{28}$ In human colon cells, we observed an autophagic response to both NS-USPIO NPs and OA-USPIO NPs, not related to the level of cell uptake of the NPs, and interestingly also to free oleic acid in HT29 cells, suggesting a protective response of the cells dependent on the exposure of cells to NPs, but not to the physicochemical characteristics of the NPs. Chaperones, such as the HSP, assist in the non-covalent folding or unfolding of others proteins, and are overexpressed in response to different environmental stress. $^{30}$ The expression of the mitochondrial chaperone HSP60, the toxic stress-induced chaperone HSP70, and the general protective chaperone HSP90 $0^{31,32}$ were evaluated. Neither of the USPIO NPs modified the HSP60 and HSP70 expression or activation state. Only the expression of HSP90 significantly increased in $\mathrm{CaCo}_{2}$ cells, but not in HT29 cells, exposed to NS-USPIO NPs and even increased at a higher level in those cells exposed to OA-USPIO NPs. Thus, the cellular response to stress, including changes in cell protein activation or expression, did not seem to depend upon the biophysical characteristics of NS-USPIO NPs and OAUSPIO NPs since these responses were mainly cell-specific. Accordingly, it has been previously demonstrated that cell reaction to NPs may depend on the biological characteristics of the cells used as models, even with cells of the same tissue origin. ${ }^{20}$ HT29 cells were generally less responsive than $\mathrm{CaCo}_{2}$ cells, possibly as a consequence of the different functional characteristics of these cells. The HT29 cells originate from a human colon adenocarcinoma and can differentiate into goblet cells, whereas $\mathrm{CaCo}_{2}$ cells, although also derived from a colon carcinoma, differentiate into cells resembling the absorptive enterocytes. Thus, we could demonstrate not only a cell-selective and NP-selective effect of USPIO NPs in the lysosomal, iron transport, and autophagic responses of colon cells, but also a protective stress response mediated by the chaperone HSP90.

Finally, the formation of large lipid vacuoles/droplets (LD) in high number was induced only by the OA-USPIO NPs. They were clearly dependent on the oleic acid as a stabilizer of these NPs, and not on the iron oxide core of the NPs or on free oleic acid. This intrinsic property of the oleic acid as a NP stabilizer may result from a high local concentration of oleic acid and/or the possibility for the NPs to be inserted into cell and cell organelle membranes, modifying the cell lipid metabolism. Thus, even if OA-USPIO NPs were poorly taken up by the cells, the oleic acid coating of USPIO NPs changed the cell response to the otherwise nontoxic NS-USPIO NPs. LDs are cytoplasmic dynamic organelles and are found in most cells, ${ }^{33}$ either under normal or pathological conditions. Their number and size varies under cell stress conditions. It has been shown that small metallic NPs, in particular cadmium, tellurium, or mercury-based NPs, or long-chain unsaturated fatty acids such as oleic acid can induce the formation of LDs under cellular oxidative stress. ${ }^{34}$ LDs are motile organelles undergoing microtubule-dependent movements in the cytoplasm and can associate with other cell organelles, including the endoplasmic reticulum. Exposure of murine glial cells to cadmium-telluride (CdTe) or InGaP/ZnS NPs, but also to oleic acid, induced the formation of LDs, some of them located close to lysosomes, possibly playing a protective function in stressed cells and a rescue role for cells exposed to CdTe NPs or controlling the cellular distribution of the InGaP/ZnS NPs. ${ }^{33,35}$ Oleic-acid-induced lipid accumulation was shown in smooth muscle cells, which became foam cells, a mechanism not limited to macrophages ${ }^{36}$ It was shown in human hepatoma cells that both oleic-acid-stabilized and unstabilized USPIO NPs induced cell arrest in the G1 phase, but OA-USPIO NPs induced less cell damage than unstabilized USPIO NPs. ${ }^{37}$ Unfortunately, in this study, the authors did not quantify the amount of NPs associated with the cells, an important factor to consider according to our previous and present results. 


\section{Conclusion}

In conclusion, the results presented here show that the biophysicochemical characteristics of USPIO NPs in their media of dispersion can predict some of the cell response to their exposure. Agglomerated NPs will be taken at high levels, inducing an iron-specific response, such as the repression of the iron transporter. Cell protective responses such as autophagy and the induction of the HSP90 chaperone are specific responses of colon cells to the stress of being exposed to NPs, independent of the biophysical characteristics of the USPIO NPs. The cell responses to the exposure to such NPs also depend on the surface properties of the NPs, in particular LDs will form in cells if the coating used to stabilize the USPIO NPs is lipophilic.

\section{Acknowledgements}

The authors want to thank the TCD CRANN Advanced Microscopy Laboratory, and in particular Dr Valerie Gerard, for the preparation of the TEM images of the received NPs and Seher Güney-Ayra for technical assistance. This work was partially supported by the European Commission 7th Framework Projects NanoImpactNet (NMP4-CA-200821853), NanoTEST (HEALTH-2007-201335), NAMDIATREAM (NMP4-LA-2010-246479), MULTIFUN (NMP4-LA-2011-262943), and NANoREG (NMP6-LA2013-310584).

\section{Author contributions}

Catherine A Schütz and Davide Staedler performed the cell experiments and participated in the writing of the paper; Catherine Chapuis Bernasconi and Blanka Halamoda Kenzaoui performed the cell experiments; Kieran CrosbieStaunton and Dania Movia performed the physicochemical characterization of the NPs; Adriele Prina-Mello designed and analyzed the physicochemical characterization of the NPs and participated in the writing of the manuscript; and Lucienne Juillerat-Jeanneret designed and supervised the project and finalized the manuscript. All authors contributed toward data analysis, drafting and revising the paper and agree to be accountable for all aspects of the work.

\section{Disclosure}

The authors report no conflicts of interest in this work.

\section{References}

1. Caruthers SD, Wickline SA, Lanza GM. Nanotechnological applications in medicine. Curr Opin Biotechnol. 2007;18(1):26-30.

2. Singh S. Nanomedicine-Nanoscale drugs and delivery systems. J Nanosci Nanotechnol. 2010;10(12):7906-7918.
3. Schütz CA, Juillerat-Jeanneret L, Mueller H, Lynch I, Riediker M; NanoImpactNet Consortium. Therapeutic nanoparticles in clinics and under clinical evaluation. Nanomedicine (Lond). 2013;8(3): 449-467.

4. Wang YX, Hussain SM, Krestin GP. Superparamagnetic iron oxide contrast agents: physicochemical characteristics and applications in MR imaging. Eur Radiol. 2001;11(11):2319-2331.

5. Wu EX, Tang H, Jensen JH. Applications of ultrasmall superparamagnetic iron oxide contrast agents in the MR study of animal models. NMR in Biomed. 2004;17(7):478-483.

6. Alexiou C, Jurgons R, Seliger C, Iro H. Medical applications of magnetic nanoparticles. J Nanosci Nanotechnol. 2006;6(9-10): $2762-2768$.

7. Weinstein JS, Varallyay CG, Dosa E, et al. Superparamagnetic iron oxide nanoparticles: diagnostic magnetic resonance imaging and potential therapeutic applications in neurooncology and central nervous system inflammatory pathologies, a review. J Cereb Blood Flow Metab. 2010;30(1):15-35.

8. Petri-Fink A, Chastellain M, Juillerat-Jeanneret L, Ferrari A, Hofmann H. Development of functionalized superparamagnetic iron oxide nanoparticles for interaction with human cancer cells. Biomaterials. 2005; 26(15):2685-2694.

9. Cengelli F, Maysinger D, Tschuddi-Monnet F, et al. Interaction of functionalized superparamagnetic iron oxide nanoparticles with brain structures. J Pharmacol Exp Ther. 2006;318(1):108-116.

10. Hanessian S, Grzyb JA, Cengelli F, Juillerat-Jeanneret L. Synthesis of chemically functionalized superparamagnetic nanoparticles as delivery vectors for chemotherapeutic drugs. Bioorg Med Chem. 2008;16(6): 2921-2931.

11. Cengelli F, Grzyb JA, Montoro A, Hofmann H, Hanessian S, JuilleratJeanneret L. Surface-functionalized ultrasmall superparamagnetic nanoparticles as magnetic delivery vectors for camptothecin. Chem Med Chem. 2009;4(6):988-997.

12. Halamoda Kenzaoui B, Vilà MR, Miquel JM, Cengelli F, JuilleratJeanneret L. Evaluation of uptake and transport of cationic and anionic ultrasmall iron oxide nanoparticles by human colon cells. Int J Nano medicine. 2012;7:1275-1286.

13. Hole P, Sillence K, Hannell C, et al. Interlaboratory comparison of size measurements on nanoparticles using Nanoparticle Tracking Analysis (NTA). J Nanopart Res. 2013;15:2101.

14. Guadagnini R, Halamoda Kenzaoui B, Cartwright L, et al. Toxicity screenings of nanomaterials: challenges due to interference with assay processes and components of classic in vitro tests. Nanotoxicology. In press 2014.

15. Beckers A, Organe S, Timmermans L, et al. Chemical inhibition of acetyl-CoA carboxylase induces growth arrest and cytotoxicity selectively in cancer cells. Cancer Res. 2007;67(17):8180-8187.

16. Staedler D, Idrizi E, Halamoda Kenzaoui B, Juillerat-Jeanneret L. Drug combinations with quercetin: doxorubicin plus quercetin in human breast cancer cells. Cancer Chemother Pharmacol. 2011;68(5): $1161-1172$.

17. Monopoli MP, Walczyk D, Campbell A, et al. Physical-chemical aspects of protein corona: relevance to in vitro and in vivo biological impacts of nanoparticles. J Am Chem Soc. 2011;133(8):2525-2534.

18. Magdolenova Z, Bilaničová D, Pojana G, et al. Impact of agglomeration and different dispersions of titanium dioxide nanoparticles on the human related in vitro cytotoxicity and genotoxicity. J Environ Monit. 2012;14(2):455-464.

19. Ahamed M, Karns M, Goodson M, et al. DNA damage response to different surface chemistry of silver nanoparticles in mammalian cells. Toxicol Appl Pharmacol. 2008;233(3):404-410.

20. Suresh AK, Pelletier DA, Wang W, Morrell-Falvey JL, Gu B, Doktycz MJ. Cytotoxicity induced by engineered silver nanocrystallites is dependent on surface coating and cell type. Langmuir. 2012;28(5): $2727-2735$.

21. Yin H, Too HP, Chow GM. The effects of particle size and surface coating on the cytotoxicity of nickel ferrite. Biomaterials. 2005;26(29): $5818-5826$. 
22. Yin H, Casey PS, McCall MJ, Fenech M. Effects of surface chemistry on cytotoxicity, genotoxicity, and the generation of reactive oxygen species induced by ZnO nanoparticles. Langmuir. 2010;26(19): 15399-15408.

23. Stergiou L, Eberhard R, Doukoumetzidis K, Hengartner MO. NER and HR pathways act sequentially to promote UVC-induced germ cell apoptosis in Caenorhabditis elegans. Cell Death Differ. 2011;18(5): 897-906.

24. Shih MF, Cherng JY. Protective effects of a chlorella-derived peptide against UVC-induced cytotoxicity through inhibition of caspase-3 activity and reduction of the expression of phosphorylated FADD and cleaved PARP-1 in skin fibroblasts. Molecules. 2012;17(8):9116-9128.

25. Bach A, Bender-Sigel J, Schrenk D, Flügel D, Kietzmann K. The antioxidant quercetin inhibits cellular proliferation via HIF-1-dependent induction of p21WAF. Antioxid Redox Signal. 2010;13(4):437-448.

26. Hentze MW, Kühn LC. Molecular control of vertebrate iron metabolism: mRNA-based regulatory circuits operated by iron, nitric oxide, and oxidative stress. Proc Natl Acad Sci US A. 1996;93(16):8175-8182.

27. Cengelli F, Voinesco F, Juillerat-Jeanneret L. Interaction of cationic ultrasmall superparamagnetic iron oxide nanoparticles with human melanoma cells. Nanomedicine (Lond). 2010;5(7):1075-1087.

28. Halamoda Kenzaoui B, Chapuis Bernasconi C, Guney-Ayra S, JuilleratJeanneret L. Induction of oxidative stress, lysosome activation and autophagy by nanoparticles in human brain endothelial cells. Biochem J. 2012;441(3):813-821.

29. Yang C, Shogren KL, Goyal R, Bravo D, Yaszemski MJ, Maran A. RNAdependent protein kinase is essential for 2-methoxyestradiol-induced autophagy in osteosarcoma cells. PLoS One. 2013;8(3):e59406.
30. Morimoto RI, Kline MP, Bimston DN, Cotto JJ. The heat-shock response: regulation and function of heat-shock proteins and molecular chaperones. Essays Biochem. 1997;32:17-29.

31. Bukau B, Horwich AL. The Hsp70 and Hsp60 chaperone machines. Cell. 1998;92(3):351-366.

32. Liu T, Daniels CK, Cao S. Comprehensive review on the HSC70 functions, interactions with related molecules and involvement in clinical diseases and therapeutic potential. Pharmacol Ther. 2012;136(3): 354-374.

33. Khatchadourian A, Maysinger D. Lipid droplets: their role in nanoparticle-induced oxidative stress. Mol Pharm. 2009;6(4): 1125-1137.

34. Napolitano M, Rivabene R, Avella M, Botham KM, Bravo E. The internal redox balance of the cells influence the metabolism of lipids of dietary origin by $\mathrm{J} 774$ macrophages: implication for foam cell formation. J Vasc Res. 2001;38(4):350-360.

35. Behrendt M, Sandros MG, McKinney RA, et al. Imaging and organelle distribution of fluorescent $\mathrm{InGaP} / \mathrm{ZnS}$ in glial cells. Nanomedicine (Lond). 2009;4(7):747-761.

36. Ma S, Yang D, Li D, Tang B, Yang Y. Oleic acid induces smooth muscle foam cell formation and enhances atherosclerotic lesion development via CD36. Lipids Health Dis. 2011;10:53.

37. Kai W, Xiaojun X, Ximing P, Zhengqing H, Qiqing Z. Cytotoxic effects and the mechanism of three types of magnetic nanoparticles on human hepatoma BEL-7402 cells. Nanoscale Res Lett. 2011;6:480. 


\section{Supplementary materials}

Table SI Antibodies and conditions for the Western blot experiments

\begin{tabular}{|c|c|c|c|c|}
\hline Primary antibody (provider) & Dilution & Buffer (w/v) & Secondary antibody & Dilution \\
\hline (Pro-) Cathepsin D (Santa Cruz Biotechnologies) & $\mathrm{I}: 2,000$ & PBS-T, I\% LF-milk & Anti-rabbit (Promega) & $\mathrm{I}: 5,000$ \\
\hline CD7I (Santa Cruz Biotechnologies) & $\mathrm{I}: 3,000$ & PBS-T, I\% LF-milk & Anti-goat (Sigma-Aldrich) & $\mathrm{I}: 5,000$ \\
\hline Cleaved PARP (Cell Signaling) & $1: 3,000$ & PBS-T, 5\% LF-milk & Anti-rabbit (Promega) & $\mathrm{I}: 5,000$ \\
\hline GST- $\pi$ (Assay Designs) & $1: 2,000$ & PBS-T, I\% LF-milk & Anti-rabbit (Promega) & $\mathrm{I}: 5,000$ \\
\hline HIF-I $\alpha$ (Cell Signaling) & $\mathrm{I}: 2,000$ & PBS-T, I\% BSA & Anti-rabbit (Promega) & $\mathrm{I}: 5,000$ \\
\hline HSP-60 (Cell Signaling) & $\mathrm{I}: 2,000$ & PBS-T, I\% BSA & Anti-rabbit (Promega) & $\mathrm{I}: 5,000$ \\
\hline HSP-70 (Cell Signaling) & $\mathrm{I}: 2,000$ & PBS-T, I\% BSA & Anti-rabbit (Promega) & $\mathrm{I}: 5,000$ \\
\hline HSP-90 (Cell Signaling) & $\mathrm{I}: 2,000$ & PBS-T, I\% LF-milk & Anti-rabbit (Promega) & $\mathrm{I}: 5,000$ \\
\hline LC3 (Novus Biologicals) & $1: 3,000$ & PBS-T, I\% LF-milk & Anti-rabbit (Promega) & $\mathrm{I}: 5,000$ \\
\hline Phospho- $\gamma \mathrm{H} 2 \mathrm{Ax}$ (Bioconcept) & $1: 5,000$ & PBS-T, I\% BSA & Anti-rabbit (Promega) & $\mathrm{I}: 5,000$ \\
\hline$\beta$-actin (Sigma-Aldrich) & $\mathrm{I}: 8,000$ & PBS-T, I\% LF-milk & Anti-rabbit (Promega) & $\mathrm{I}: 10,000$ \\
\hline
\end{tabular}

Notes: Santa Cruz Biotechnologies, Dallas, TX, USA; Cell Signaling Technology, Danvers, MA, USA; Assay Designs, Ann Arbor, MI, USA; Novus Biologicals, Atlanta, GA, USA; BioConcept, Allschwil, Switzerland; Sigma-Aldrich, St Louis, MO, USA; Promega, Madison, WI, USA.

Abbreviations: BSA, bovine serum albumin; CD7I, transferrin receptor; LF, low fat; GST- $\pi$, glutathione S-transferase- $\pi$; $\gamma H 2 A X$, phospho-histone $H 2 A X$; HIF-I $\alpha$, hypoxiainducible factor I- $\alpha$; HSP, heat shock protein; PARP, poly(ADP-ribose) polymerase; PBS-T, PBS-Triton X-100; w/v, weight/volume.

Table S2 Complete characterization of the NS-USPIO NPs and OA-USPIO NPs in unconditioned biological media

\begin{tabular}{|c|c|c|c|c|c|c|c|}
\hline & \multirow{2}{*}{$\frac{\text { DI water }}{50 \mu \mathrm{g} / \mathrm{mL}}$} & \multicolumn{3}{|l|}{ FCS } & \multicolumn{3}{|c|}{ DMEM + FCS } \\
\hline & & $25 \mu \mathrm{g} / \mathrm{mL}$ & $50 \mu \mathrm{g} / \mathrm{mL}$ & $100 \mu \mathrm{g} / \mathrm{mL}$ & $25 \mu \mathrm{g} / \mathrm{mL}$ & $50 \mu \mathrm{g} / \mathrm{mL}$ & $100 \mu \mathrm{g} / \mathrm{mL}$ \\
\hline \multicolumn{8}{|l|}{ NS-USPIO NPs } \\
\hline NTA size \pm SD (nm) & $223 \pm 81$ & $338 \pm 303$ & $287 \pm 127$ & $313 \pm 156$ & $197 \pm 150$ & $|3| \pm 103$ & $196 \pm 172$ \\
\hline NTA PDI & 0.13 & 0.80 & 0.19 & 0.25 & 0.58 & 0.61 & 0.77 \\
\hline DLS size \pm SD $(\mathrm{nm})$ & $236.8 \pm 2.4$ & $38.7 \pm 4.1$ & $64.1 \pm 0.16$ & $116.5 \pm 11.1$ & $2,415 \pm 235$ & $4,189 \pm 1009$ & $4,087 \pm 1489$ \\
\hline DLS zeta \pm SD $(\mathrm{mV})$ & $(-68.6 \pm 7.8)$ & $(-10.6 \pm 0.5)$ & $(-11.1 \pm 0.6)$ & $(-11.8 \pm 0.8)$ & $(-9.9 \pm 0.9)$ & $(-11.6 \pm 1.6)$ & $(-2.3 \pm 0.4)$ \\
\hline $\mathrm{DLS} P D I \pm S D$ & $0.22 \pm 0.02$ & $0.99 \pm 0.02$ & $\mathrm{I} \pm 0$ & $\mathrm{I} \pm 0$ & $0.47 \pm 0.03$ & $0.20 \pm 0.20$ & $0.59 \pm 0.32$ \\
\hline DLS mobility $\pm S D(\mu \mathrm{mcm} / \mathrm{Vs})$ & $3.70 \pm 0.08$ & $(-0.83 \pm 0.04)$ & $(-0.87 \pm 0.05)$ & $(-0.92 \pm 0.06)$ & $(-0.78 \pm 0.07)$ & $(-0.91 \pm 0.12)$ & $(-0.18 \pm 0.03)$ \\
\hline \multicolumn{8}{|l|}{ OA-USPIO NPs } \\
\hline NTA size \pm SD (nm) & $119 \pm 44$ & $189 \pm 72$ & $176 \pm 77$ & $192 \pm 76$ & $|74 \pm 9|$ & $325 \pm 118$ & $181 \pm 112$ \\
\hline NTA PDI & 0.13 & 0.15 & 0.19 & 0.15 & 0.27 & 0.13 & 0.38 \\
\hline $\mathrm{DLS}$ size $\pm \mathrm{SD}(\mathrm{nm})$ & $110.0 \pm 0.15$ & $94.1 \pm 7.0$ & $115.5 \pm 6.1$ & $116.4 \pm 4.6$ & $1,436 \pm 167$ & $2,568 \pm 592$ & $2,525 \pm 240$ \\
\hline DLS zeta \pm SD $(m V)$ & $(-48.6 \pm 0.6)$ & $(-10.6 \pm 0.8)$ & $(-10.8 \pm 0.8)$ & $(-I I . I \pm I .0)$ & $(-23.5 \pm 1.8)$ & $(-26.7 \pm 7.3)$ & $(-24.8 \pm 2.3)$ \\
\hline DLS PDI $\pm S D$ & $0.17 \pm 0.01$ & $0.55 \pm 0.09$ & $0.48 \pm 0.04$ & $0.47 \pm 0.0 \mathrm{I}$ & $0.95 \pm 0.06$ & $0.5 \mathrm{I} \pm 0.0 \mathrm{I}$ & $0.7 I \pm 0.4 I$ \\
\hline DLS mobility $\pm S D(\mu \mathrm{mcm} / V \mathrm{~s})$ & $(-3.8 \mathrm{I} \pm 0.05)$ & $(-0.83 \pm 0.06)$ & $(-0.85 \pm 0.06)$ & $(-0.87 \pm 0.07)$ & $(-1.84 \pm 0.14)$ & $(-2.09 \pm 0.24)$ & $(-1.94 \pm 0.18)$ \\
\hline
\end{tabular}

Abbreviations: DI, deionized water; DLS, dynamic light scattering; DMEM, Dulbecco's Modified Eagle's Medium; FCS, fetal calf serum; NS-USPIO NPs, non-stabilized ultrasmall superparamagnetic iron oxide nanoparticles; NTA, nanoparticle tracking analysis; OA-USPIO NPs, oleic-acid-stabilized ultrasmall superparamagnetic iron oxide nanoparticles; PBS, phosphate-buffered saline; PDI, polydispersity index; SD, standard deviation. 
Table S3 Complete characterization of the NS-USPIO NPs and OA-USPIO NPs in colon cell-conditioned media

\begin{tabular}{|c|c|c|c|c|c|c|}
\hline & \multicolumn{3}{|l|}{$\mathrm{CaCo}_{2}-\mathrm{CM}$} & \multicolumn{3}{|l|}{ HT29-CM } \\
\hline & $25 \mu \mathrm{g} / \mathrm{mL}$ & $50 \mu \mathrm{g} / \mathrm{mL}$ & $100 \mu \mathrm{g} / \mathrm{mL}$ & $25 \mu \mathrm{g} / \mathrm{mL}$ & $50 \mu \mathrm{g} / \mathrm{mL}$ & $100 \mu \mathrm{g} / \mathrm{mL}$ \\
\hline \multicolumn{7}{|l|}{ NS-USPIO NPs } \\
\hline NTA size \pm SD (nm) & $254 \pm 103$ & $216 \pm 97$ & $244 \pm 102$ & $285 \pm 103$ & $250 \pm 97$ & $265 \pm 102$ \\
\hline NTA PDI & 0.16 & 0.20 & 0.18 & 0.14 & 0.15 & 0.14 \\
\hline DLS size \pm SD $(\mathrm{nm})$ & $142.4 \pm 2.0$ & $189.2 \pm 1.7$ & $281.7 \pm 50.9$ & $132.8 \pm 5.2$ & $150.5 \pm 0.6$ & $204.2 \pm 7.4$ \\
\hline DLS zeta \pm SD $(\mathrm{mV})$ & $(-10.9 \pm 1.0)$ & $(-11.2 \pm 0.7)$ & $(-11.5 \pm 0.8)$ & $(-11.3 \pm 0.9)$ & $(-13.2 \pm 0.8)$ & $(-11.6 \pm 0.9)$ \\
\hline DLS PDI $\pm S D$ & $0.60 \pm 0.01$ & $0.50 \pm 0.02$ & $0.50 \pm 0.10$ & $0.40 \pm 0.07$ & $0.26 \pm 0.01$ & $0.3 I \pm 0.04$ \\
\hline $\mathrm{DLS}$ mobility $\pm \mathrm{SD}(\mu \mathrm{mcm} / \mathrm{Vs})$ & $(-0.86 \pm 0.07)$ & $(-0.88 \pm 0.05)$ & $(-0.90 \pm 0.06)$ & $(-0.89 \pm 0.07)$ & $(-1.03 \pm 0.06)$ & $(-0.91 \pm 0.07)$ \\
\hline \multicolumn{7}{|l|}{ OA-USPIO NPs } \\
\hline NTA size \pm SD (nm) & $179 \pm 783$ & $206 \pm 90$ & $200 \pm 88$ & $188 \pm 78$ & $157 \pm 90$ & $195 \pm 88$ \\
\hline NTA PDI & 0.19 & 0.19 & 0.19 & 0.19 & 0.21 & 0.21 \\
\hline DLS size \pm SD $(\mathrm{nm})$ & $98.9 \pm 3.9$ & $107.8 \pm 5.5$ & $120.2 \pm 1.6$ & $95.0 \pm 1.6$ & $104.0 \pm 20.6$ & $139.2 \pm 5.2$ \\
\hline DLS zeta \pm SD $(\mathrm{mV})$ & $(-12.2 \pm 0.7)$ & $(-12.4 \pm 1.5)$ & $(-14.0 \pm 1.4)$ & $(-12.2 \pm 0.4)$ & $(-12.9 \pm 1.3)$ & $(-11.8 \pm 0.8)$ \\
\hline DLS PDI \pm SD & $0.32 \pm 0.02$ & $0.29 \pm 0.01$ & $0.3 I \pm 0.06$ & $0.28 \pm 0.01$ & $0.24 \pm 0.01$ & $0.34 \pm 0.0 \mathrm{I}$ \\
\hline DLS mobility $\pm S D(\mu \mathrm{mcm} / \mathrm{Vs})$ & $(-0.95 \pm 0.05)$ & $(-0.97 \pm 0.11)$ & $(-1.10 \pm 0.1 I)$ & $(-0.95 \pm 0.03)$ & $(-1.01 \pm 0.10)$ & $(-0.93 \pm 0.06)$ \\
\hline
\end{tabular}

Notes: Zeta potentials and mobility are indicative only, since the NPs agglomerate in media. Means \pm sd of N=3 measurements. FCS: $10 \%$ FCS in PBS. DMEM + FCS: I0\% FCS in DMEM cell culture medium.

Abbreviations: $\mathrm{CaCO}_{2}-\mathrm{CM}$, culture medium conditioned by $\mathrm{CaCo}_{2}$ cells; DLS, dynamic light scattering; DMEM, Dulbecco's Modified Eagle's Medium; FCS, fetal calf serum; HT29-CM, culture medium conditioned by HT29 cells; NS-USPIO NPs, non-stabilized ultrasmall superparamagnetic iron oxide nanoparticles; NTA, nanoparticle tracking analysis; OA-USPIO NPs, oleic-acid-stabilized ultrasmall superparamagnetic iron oxide nanoparticles; PDI, polydispersity index; SD, standard deviation.

\section{Publish your work in this journal}

The International Journal of Nanomedicine is an international, peerreviewed journal focusing on the application of nanotechnology in diagnostics, therapeutics, and drug delivery systems throughout the biomedical field. This journal is indexed on PubMed Central, MedLine, CAS, SciSearch $®$, Current Contents ${ }^{\circledR} /$ Clinical Medicine,
Journal Citation Reports/Science Edition, EMBase, Scopus and the Elsevier Bibliographic databases. The manuscript management system is completely online and includes a very quick and fair peer-review system, which is all easy to use. Visit http://www.dovepress.com/ testimonials.php to read real quotes from published authors. 